\title{
Exkurs: Alejo Carpentier, eine karibische Vision Haitis, die Frage des Rassismus und das Konzept der Transkulturation
}

Mit dem kubanischen Schriftsteller und Musikologen Alejo Carpentier und insbesondere seinem Roman El siglo de las luces gelangen wir mehr als ein Jahrhundert später zu einer ganz anderen Beschäftigung mit der Präsenz der Französischen Revolution in der Karibik. Der Roman müsste eigentlich auf Deutsch Das Jahrhundert der Aufklärung heißen. Aus Angst vor einer Verwechslung mit einem Sachbuch aber wählte der Verlag den reißerischen Titel Explosion in der Kathedrale. Carpentiers Bemühen um ein neues Verständnis der Haitianischen Revolution, das er bereits im Verlauf der vierziger Jahre in die Arbeit an seinem Roman El reino de este mundo einfließen ließ, ist ein Beispiel für eine interne Relationalität interlingualen Zuschnitts im Umfeld eines historischen Paradigmas, das für den gesamten karibischen Raum von allergrößter Bedeutung war.

Wir haben es folglich in diesem Falle - wie im Verlauf der gesamten Vorlesung - mit Phänomenen einer starken Bezüglichkeit und Interrelation zwischen verschiedenen romanischen Literaturen der Welt $\mathrm{zu}$ tun, in diesem Beispiel zwischen französisch- und spanischsprachigen Literaturen und dem 19. sowie dem 20. Jahrhundert. Im Verhältnis zu Victor Hugo, den Alejo Carpentier als „poeta doctus“ sehr gut kannte und dessen Bug-Jargal er zweifelsohne sehr genau gelesen hatte, schreibt der kubanische Schriftsteller aus der - wie man es früher nannte - weit entfernten Peripherie der romanischen Welt aus einer anderen, grundlegend abweichenden Perspektive auf die historischen Ereignisse im transatlantischen Spannungsfeld. Dabei bezog sich Alejo Carpentier ebenso auf die spanisch- wie die französischsprachige Karibik, aber auch auf die englischsprachige und niederländische Inselwelt, womit er im Rückgriff auf das 18. Jahrhundert gleich mindestens vier verschiedene Kolonialreiche aufrief. Und dieser komplexe historische und kulturelle Hintergrund ist in der Tat notwendig, will man den Verlauf wie die Bedeutung der Haitianischen Revolution für beide Seiten des Atlantik adäquat erfassen.

Kein Zweifel: The Empire Writes Back, wie es ein wichtiger postkolonialer ,Klassiker ${ }^{6}$ Ende der achtziger Jahre formulierte! ${ }^{1}$ Allerdings tat dies das Kolonialreich in der französisch- und vor allem in der spanischsprachigen Welt schon Ende des 18. Jahrhunderts, was mit den Theoriebildungen im englischsprachigen

1 Vgl. Ashcroft, Bill / Griffiths, Gareth / Tiffin, Helen: The Empire Writes Back. Theory and Practice in Post-Colonial Literatures. London: Routledge 1989.

Ә Open Access. (C) 2021 Ottmar Ette, publiziert von De Gruyter. (c) BY-NC-ND Dieses Werk ist lizensiert unter einer Creative Commons Namensnennung - Nicht-kommerziell - Keine Bearbeitung 4.0 International Lizenz. https://doi.org/10.1515/9783110703443-011 
Raum nicht einfach in Übereinstimmung zu bringen ist. Bei den Postcolonial Studies haben wir es daher in weiten Bereichen mit Ansätzen zu tun, die auf einem für die romanischen Literaturen der Welt größtenteils inadäquaten historischen Befund aufruhen und vor allem auf Grund einer Feldmacht der USA vorübergehend durchgesetzt wurden. Wenn dies auch nicht der adäquate Ort ist, eine zielführende Auseinandersetzung mit den Postcolonial Studies zu befeuern, möchte ich an dieser Stelle unserer Vorlesung doch darauf hinweisen, dass wir sehr wohl über postkoloniale Aspekte werden sprechen müssen, freilich nicht im Sinne dieser bestenfalls für die Anglophonie geltenden Studien, die ihren Zenit längst überschritten haben.

Ebenso wenig ist hier der Ort, sich in einer Vorlesung über das 19. Jahrhundert mit dem Leben des am 26. Dezember 1904 in La Habana geborenen und am 24. April 1980 in Paris verstorbenen kubanischen Schriftstellers Alejo Carpentier $\mathrm{zu}$ beschäftigen. Einige wenige, für uns wichtige Biographeme aber seien gestattet. Carpentiers Vater war ein französischer Architekt, seine Mutter gebürtige Russin; und in der reichen Bibliothek seines Vaters kam der junge Carpentier, der in Kuba französisch erzogen wurde, aber auf der Straße Spanisch sprach, schnell in Kontakt mit Werken insbesondere der französischen Romantik. Von seinen literarisch wie musisch interessierten Eltern erbte er eine Leidenschaft für die Musik, mit der sich Carpentier ein Leben lang intensiv beschäftigte. ${ }^{2}$

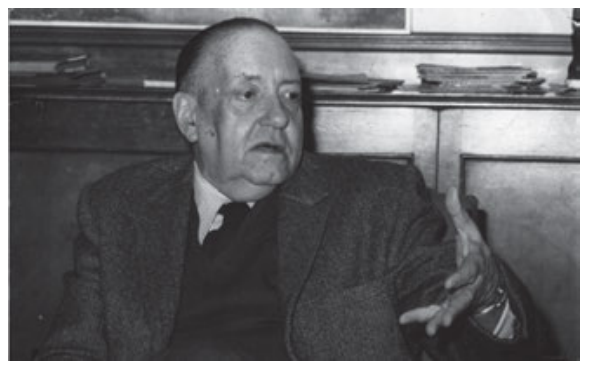

Abb. 25: Alejo Carpentier (Lausanne, 1904 - Paris, 1980).

Alejo Carpentier war der französischen Welt und insbesondere Paris stets eng verbunden - nicht nur, weil er dort seit 1928 elf Jahre im Exil weilte. Denn er arbeitete später für die Kubanische Revolution als Kulturattaché und Botschaftsrat in der französischen Hauptstadt, von wo aus er die Ereignisse engagiert und zugleich aus sicherer Entfernung kommentierte. Carpentier war aufs Engste mit

2 Vgl. zu Leben und Werk Alejo Carpentiers die Überblicksstudie von Herlinghaus, Hermann: Alejo Carpentier. Persönliche Geschichte eines literarischen Moderneprojekts. München: Edition text+kritik 1991. 
den französischen Surrealisten, aber auch mit der Elite der spanischen Literatur bekannt und schrieb - wie zuvor schon in La Habana - für wichtige Zeitschriften und Periodika. Man darf ohne Übertreibung sagen, dass Carpentier das Who is Who der zeitgenössischen Literatur und Kunst in Europa, aber auch in Lateinamerika kannte und die kulturelle Szene beider Welten wie nur wenige Intellektuelle überblickte.

1939 in der Hoffnung auf eine linke Politik nach Kuba zurückgekehrt, erhielt er eine Professur für Musikologie an der Universität von Havanna. Doch längst hatte er sich als Schriftsteller und Intellektueller einen Namen gemacht, stand mit kubanischen Dichtern wie Nicolás Guillén und José Lezama Lima oder kubanischen Künstlern wie Wifredo Lam, aber auch mit kubanischen Komponisten wie Amadeo Roldán oder Alejandro García Caturla in engem Austausch. Er interessierte sich bereits seit den zwanziger Jahren für schwarze Kunst und Kultur sowie für kulturgeschichtliche wie anthropologische Forschungen auf diesem Gebiet. Sein erster Roman beschäftigte sich 1933 unter dem Titel ¡Ecue-Yamba-o! mit den transkulturierten - ich komme auf diesen Begriff zurück - schwarzen Kulturen auf Kuba. 1943 reiste er nach Haiti, eine Reise, die ihn zutiefst prägte und in ihm das Konzept der „Wunderbaren Wirklichkeit“, des „real maravilloso“, sowie seinen bereits erwähnten Roman Das Reich von dieser Welt (1949) entstehen ließ.

Nach Ende des Zweiten Weltkrieges siedelte er nach Venezuela über und bekleidete bald einen Lehrstuhl für Kulturgeschichte, zählte in diesen Jahren aber bereits zu den bekanntesten Schriftstellern der Literaturen Lateinamerikas. 1959 bekannte er sich zur Kubanischen Revolution und kehrte nach Havanna zurück, wo er wichtige Positionen im Verlagswesen wie im Schriftstellerverband übernahm. 1962 erschien sein Roman El siglo de las luces, in welchem er sich mit dem Zeitalter der Französischen wie der Haitianischen Revolution und den transatlantischen Beziehungen im Zeichen seines Konzepts des „real maravilloso“ auseinandersetzte. Ab 1966 lebte er als Kulturattaché der kubanischen Botschaft wieder in Paris, rundete dort sein großes Romanwerk mit weiteren breit rezipierten Erzähltexten ab und pflegte bis zu seinem Tod im Jahr 1980 seine vielfältigen literarischen und kulturellen Freundschaften.

Lassen Sie uns nun zu Carpentiers Roman El Siglo de las Luces kommen, der - wie bereits erwähnt - 1962 erschien, aber in seiner Entstehung zumindest bis ins Jahr 1958 zurückreicht! Es geht in diesem komplexen Erzählwerk nicht um ein „Jahrhundert der Aufklärung“ oder „Siècle des Lumières“, wie diese Epoche in Europa oft bezeichnet wird, sondern um ein Jahrhundert von Massakern und Gräueln, Terror und Totschlag, die im Zeichen der Revolutionen stehen. Denn mit Blick auf die gesamte Karibik zieht der Roman eine dunkle, ja katastrophale Bilanz, die auch für die Zukunft der transatlantischen Beziehungen wenig Gutes verheißt. Denn unter dem Banner der Französischen Revolution wird Victor 
Hugues, ein Händler aus Haiti, die Ideen der Aufklärung und die Praktiken der Revolution in die Neue Welt bringen und zu einer Art skrupellosem Robespierre der französischen Antillen avancieren.

Es geht in diesem Roman vorrangig um die französisch- und spanischsprachige Karibik, wobei ich Sie nicht mit allzu vielen Handlungselementen langweilen will. Wichtig ist gleichwohl, dass sich alles von Beginn an um die aus reichem spanischem Elternhaus auf Kuba stammenden Geschwister Carlos und Sofía zusammen mit ihrem Vetter Esteban dreht. Von Robespierre persönlich erhält Victor Hugues, der zuvor die fünfzehnjährige Sofía verführte und danach vor dem Zugriff der kolonialspanischen Behörden flüchtete, den Auftrag, auf den französischen Antilleninseln die Revolution einzuführen. Und das tut er dann auch mit aller Konsequenz und Brutalität. Denn sein Credo ist die Guillotine, die er in die Karibik verfrachten lässt.

Es gibt kein einziges der großen Probleme des Jahrhunderts der Aufklärung, das in diesem mit historisch korrekt recherchierten Details gespickten Roman nicht angesprochen und diskutiert werden würde: Die Leserschaft wird von Carpentier in eine sorgsam vorbereitete Auseinandersetzung mit - so könnten wir sagen - der Dialektik der Aufklärung aus karibischer Sicht geladen. Insofern ist dieser Erzähltext nicht nur ein historischer, sondern zugleich ein philosophischer Roman, der die Conditio humana am Beispiel der Welt der Antillen in einem Dekor vor Augen führt, das sich ganz im Sinne Carpentier'scher Ästhetik in tropischer Fülle und neobarocker Überfülle präsentiert.

Innerhalb der Figurenkonstellationen verkörpert die schöne Sofía in einem ganz etymologischen Sinne die Weisheit und übernimmt die Standorte der Philosophie, die sich gegenüber der handfesten und skrupellosen Politik der Figur des Victor Hugues manifestiert, aber auch den Intellektuellen einen eigenen Bereich in dieser Welt zu sichern versucht. Dies ist nicht zuletzt deshalb notwendig, weil sich dieser philosophische Roman historisch vor dem Hintergrund der Französischen wie der Haitianischen Revolution, zeitgeschichtlich aber auch vor jenem der Kubanischen Revolution situiert, für deren kritische und zugleich positive Beleuchtung er zweifellos sorgt. Denn in dieser kubanischen ,Dialektik der Aufklärung' geht es im Wesentlichen um die Herausforderungen des Menschen in einem Kontext von Revolutionen: Die Geschichte der Menschheit ist radikal zukunftsoffen geworden, kein Ancien Régime scheint mehr alles zu bremsen und zu behindern.

El siglo de las luces ist zweifellos ein historischer Roman, der sich einer Vielzahl historischer Figuren bedient, obwohl er eingebettet ist in eine Ästhetik und Wirkkraft des Wunderbaren, des „real maravilloso“, die es zu einer Dimension des Wirklichen werden lässt. In Carpentiers Augen schließen sich das Historische und das Wunderbare keineswegs aus, sondern bilden eine in sich höchst wider- 
sprüchliche Realität, die nicht allein mit Hilfe der menschlichen Ratio durchdrungen werden kann. So ist das historische Setting, das Carpentier für seinen Roman entwirft und erfindet, präzise und detailgetreu ausgestaltet und lässt zugleich die Ereignisse in Europa aus dem Blickwinkel der Karibik erstehen.

Als Beispiel dieser Anlage möchte ich Ihnen kurz den Schlussteil eines Romankapitels vorstellen. Die Nachrichten aus Europa und vor allem aus Frankreich sind allesamt für die Romanfiguren von höchstem Interesse, aber eine erscheint ganz besonders außergewöhnlich:

Sie waren interessant, unerhört, außergewöhnlich, gewiss. Aber keine von ihnen war so beträchtlich, so sensationell wie jene, die sich auf die Flucht des Königs und seine Verhaftung in Varennes bezog. Es war etwas so Riesiges, so Neuartiges für jedweden Geist, dass die Worte „König“ und „Verhaftung“ sich nicht miteinander verbinden und eine unmittelbar zulässige Denkmöglichkeit herstellen wollten. Ein Monarch verhaftet, schmachvoll, erniedrigt, den Wachen des Volkes übergeben, das er zu regieren vorgab, aber sich dazu als unwürdig erwies! Die größte Krone, die bedeutendste Macht, das höchste Zepter des ganzen Universums von zwei Gendarmen herbeigezerrt. „Und ich handele mit geschmuggelten Seidenstoffen, wo sich derartige Dinge in der Welt abspielen“, sagte Victor, der sich die Hände an den Kopf hielt. „Dort wohnte man der Geburt einer neuen Menschheit bei ...“ Vorangetrieben von der nächtlichen Brise schiffte die Borée unter einem mit so hellen Sternen bestückten Himmel langsam weiter, so dass sich die Gebirge des Ostens in dichte Finsternisse hüllten, welche die reine Zeichnung ihrer Konstellationen durchschnitten. Zurück blieben die Feuersbrünste eines Tages. Gen Osten erhob sich aufrecht und großartig, wie von kundigen Augen gerade noch erkannt, die Feuersäule, welche den Marsch in jedes Gelobte Land leitete. ${ }^{3}$

In dieser Passage aus El Siglo de las Luces wird deutlich, welchen Eindruck die revolutionären Ereignisse in Frankreich sowie der Sturz und die Verhaftung des Königs, der schon bald die Enthauptung folgte, auf die Einbildungskraft jener Menschen in der Karibik haben musste. Diese hatten an ein gottgewohntes System und an eine gleichsam ewige Macht in der europäischen Zentrale, in der „Métropole“, geglaubt. Die Zukunft war mit einem Schlag offen, alles schien nunmehr möglich. War die Wirkung der Ereignisse in ganz Europa ungeheuer, so musste sie noch stärker an der sogenannten Peripherie des Kolonialreiches empfunden werden, wo diese Macht als noch unerschütterlicher erschienen war. Damit lag wie bei Victor Hugues - der Gedanke nahe, sich nicht länger mit dem Klein-Klein der eigenen Existenz zufrieden zu geben, sondern sich direkt in die Geschehnisse einzumischen, um an diesem Menschheitsabenteuer teilzunehmen und womöglich noch eigenen Gewinn herauszuschlagen.

3 Carpentier, Alejo: El Siglo de las Luces. Barcelona: Editorial Seix Barral 1981, $86 \mathrm{f}$. 
In diesem Zitat, welches das erste Kapitel dieses historischen Romans abschließt, werden gleichsam die Französische Revolution und die sich ankündigende und bereits angelaufene Haitianische Revolution gleichsam ineinandergeschoben und ineinandergeblendet, wobei der gelehrte kubanische Verfasser an die Wichtigkeit des Bildes vom ewig unveränderlichen gestirnten Himmel für einen Aufklärungsphilosophen wie Immanuel Kant gedacht haben dürfte. Es ist der Augenblick, in dem sich Victor Hugues darüber klar wird, in die große Geschichte eingreifen zu müssen. Denn der französische Stoffhändler und Kaufmann aus Port-au-Prince, der mit allerlei illegalen Geschäften nach Kuba gekommen war, befindet sich auf dem Rückweg zu jenem Ostteil einer Insel, die noch Saint-Domingue geheißen hatte, als er sie verließ, und die er nun als Haiti wieder betreten sollte. Die Geschichte hatte revolutionär an Fahrt aufgenommen, und der ambitionierte Hugues wollte an dieser neuen Menschheitsgeschichte seinen aktiven Anteil haben.

Vom Ostteil der Insel Kuba zum Westteil der Insel Hispaniola ist es - wie Sie jeder Karte der Karibik entnehmen können - nicht sehr weit, und an schönen Tagen kann man vom Gebirge im kubanischen „Oriente“ aus hinüberschauen nach Haiti, in dessen Norden nun, für kundige Augen bereits sichtbar, Feuer und Rauch aufsteigen. Sind sie die Zeugen einer neuen Zeit? Victor Hugues ist sich in dieser Frage sicher. Zugleich wird sich der Kaufmann und Händler der Tatsache bewusst, dass er in dieses unglaubliche, zuvor nicht vorstellbare historische Geschehen in keiner Weise einbezogen war, sondern noch immer kleingeistig mit Schmuggelware handelte, als wäre nie ein Umsturz aller Verhältnisse geschehen. Doch eine neue Zeitrechnung ist angebrochen: jene der Revolution, die selbstverständlich auch ihren eigenen Kalender entwerfen wird.

Victor Hugues wird nicht lange untätig bleiben: Schon bald ergreift er die Initiative und wird zum Robespierre der Antillen. Interessant ist die Schlussbemerkung, die Carpentiers Erzähler uns an dieser Stelle nicht verbergen kann oder will. Es ist die biblische und zugleich prophetische Einsicht, dass jedes Gelobte Land immer schon seine Feuer- und Rauchsäulen vorausschickt, dass also das Erreichen des Erträumten immer mit dem Durchlaufen von Geschehnissen verbunden ist, die das Kommende ankündigen und doch im Zeichen einer höchst rückwärtsgewandten Grausamkeit und Zerstörungswut stehen.

Der schöne Titel von Carpentiers Roman, der ironisch vom „Jahrhundert der Aufklärung" und dem hellen Lichte dieses Zeitalters spricht, lässt das Gelobte Land der Aufklärung just an jenem Vorabend einer Revolution erscheinen, die wie im Falle der Haitianischen Revolution - dieses Grauen, diese Flammen und diesen Rauch im Übermaß erzeugen sollte. Doch Carpentier verkündet uns noch mehr. Der längst bekannte, intellektuelle Autor', der sehr genau die Vorgänge in jener Sierra Maestra im Osten Kubas orchestrierte, von der aus man - zumindest 
vom Pico Turpino aus, den Fidel Castro erklomm - Haiti sehen kann, verkündet gleichsam hinter der Stimme des Erzählers das Herannahen jener anderen Kubanischen Revolution, für die Alejo Carpentier selbst in jenen Jahren Partei ergreifen sollte. War diese Revolution, die ihre festen Strukturen aufbaute, aber weit mehr als eine Million Menschen ins Exil trieb, wirklich ein Gelobtes Land? Ja, das Gelobte Land der Revolution wird schon bald nicht wenige seiner Kinder fressen!

El Siglo de las Luces ist ohne jede Frage ein historischer Roman. Und Victor Hugues, die sicherlich zentrale Figur des Romans, ist auch fraglos eine historische Gestalt. Alejo Capentier hat sich in einem dem Roman hinzugefügten didaktischen Annex explizit zur Historizität dieses Victor Hugues geäußert, der ursprünglich aus einfachen Marseiller Verhältnissen stammte, die sich ihm bietenden Chancen aber sofort erkannte. So beginnt sein Eintritt in die Geschichte in Großbuchstaben:

\begin{abstract}
Sein wirklicher Eintritt in die Geschichte war die Nacht, in welcher seine Niederlassung von den haitianischen Revolutionären angezündet wurde. Ab diesem Zeitpunkt können wir seine Laufbahn Schritt für Schritt verfolgen, so wie sie in diesem Buch erzählt wird. Die Kapitel, welche der Eroberung von Guadeloupe gewidmet sind, folgen einem präzisen chronologischen Schema. Was über seinen Krieg gegen die Vereinigten Staaten gesagt wird welchen die damaligen Yankees den „Brigantenkrieg“ nannten - und was die Aktion der Korsaren mit ihren Eigennamen und den Namen ihrer Schiffe angeht, so stützt sich dies alles auf Dokumente, die vom Verfasser auf Guadeloupe und in Bibliotheken auf Barbados gesammelt wurden sowie auf kurze, aber instruktive Referenzen, die in Werken lateinamerikanischer Autoren aufgefunden wurden und die eher im Vorübergehen Victor Hugues' erwähnen.

[...] dies bietet uns das Bild einer außerordentlichen Figur, die schon durch ihr eigenes Verhalten eine dramatische Dichotomie herstellt. Aus diesem Grunde hielt es der Verfasser für aufschlussreich, die Existenz dieser unbekannten historischen Figur in einem Roman zu enthüllen, der gleichzeitig das gesamte Ambiente der Karibik vor Augen führen sollte. ${ }^{4}$
\end{abstract}

Der in wissenschaftlichen Recherchen geschulte Alejo Carpentier betont in dieser Passage nicht nur die Historizität seiner Figur, sondern selbstverständlich auch seine eigene historische Beschlagenheit und die Unterfütterung des Romans mit Dokumenten, die gleichsam über die gesamte Karibik verstreut und von ihm gesammelt worden waren. Der Roman tritt hier in das Schweigen der Historiographie ein: Er spricht dort, wo sie schweigt oder verschweigt, um ein neues, lebendigeres Bild der Geschichte zu entwerfen. Das ist an dieser Stelle mitnichten bloße Rivalität mit der Geschichtsschreibung, sondern zugleich auch eine andere Herangehensweise: Denn die Literaturen der Welt sind keineswegs wie

4 Carpentier, Alejo: El Siglo de las Luces, S. 344 f. 
die Geschichte eine Darstellung dessen, wie es gewesen ist, sondern - wie bereits Aristoteles in seiner Poetik formulierte - wie es hätte sein können. Aber mehr noch als diese Unterscheidung ist die Kunst des Romans auch nicht die simple Darstellung von Wirklichkeit, sondern die ästhetische Darstellung gelebter oder lebbarer Wirklichkeiten.

Dieses von Alejo Carpentier und den Schriftsteller*innen aus Lateinamerika entworfene Bild der Geschichte aber ist nun nicht länger an den Interessen und Fragestellungen der Metropole, sondern vor allem an den Perspektiven und Bedürfnissen der Karibik - und zwar der gesamten Karibik - ausgerichtet. Der kubanische Autor weiß sich dabei in einer langen Tradition lateinamerikanischen Schreibens, auf die er zurückgreifen kann. Wie die von ihm gesammelten Dokumente die verschiedensten Bereiche der Karibik erfassen, so will auch dieser Roman Alejo Carpentiers mit dem so umfassenden Titel El Siglo de las Luces das Phänomen Karibik nicht auf einen einzigen sprachlichen Bereich beschränkt wissen. Denn die fraktale Inselwelt der Karibik ist der vielleicht spannendste und zugleich überzeugendste Ort, der einem plastisch vor Augen führt, dass eine Geschichte nicht anhand nationaler Grenzlinien oder Sprachgrenzen erzählt und ausgerichtet werden darf, sondern unbedingt grenzüberschreitend - und ich füge hinzu: transareal - ausgerichtet sein muss. Wir werden zu einem späteren Zeitpunkt noch sehen, was unter dieser Transarealität und unter TransArea Studies genauer zu verstehen ist. ${ }^{5}$ Für unsere multiperspektivische Herangehensweise ist in dieser Vorlesung aber entscheidend, dass wir aus verschiedenen Blickwinkeln grenzüberschreitende Bewegungen nachzuvollziehen suchen, die das Phänomen der Bewegung als solches in den Mittelpunkt rücken. Denn an die Stelle einer bislang dominanten raumgeschichtlichen Sichtweise soll ein bewegungsgeschichtliches Verständnis treten.

Revolutionen sind für den kubanischen Schriftsteller unverzichtbar, zugleich aber keineswegs das Allheilmittel für krankhafte geschichtliche Entwicklungen. Spätestens im fünften Kapitel wird - gleichsam in Form eines Echos auf den oben angeführten Aufbruch des Victor Hugues am Ende des ersten Kapitels - in der Stimme des jungen Intellektuellen Esteban deutlich, dass die Hoffnungen auf eine künftig bessere, gerechtere Zukunft und Geschichte auch mit dieser Revolution und mit diesen Revolutionen - nicht eingelöst worden seien. Er erinnert verbittert an die vielen Toten, die jene ambitionierten Hoffnungen, jene Utopien gekostet hätten. Und er leitet über zu einer Kritik an seinem eigenen, am 18. Jahrhundert -

5 Vgl. Ette, Ottmar: TransArea. Eine literarische Globalisierungsgeschichte. Berlin - Boston: Walter de Gruyter 2012. 
und vielleicht darf auch das zurückliegende 20. Jahrhundert sich von diesen Einschätzungen und Aussagen durchaus angesprochen und getroffen fühlen:

\begin{abstract}
„Dieses Mal ist die Revolution gescheitert. Vielleicht klappt es beim nächsten Mal. Um mich aber, sobald sie ausbricht, zu schnappen, werden sie mich mit Laternen am Mittag suchen müssen. Hüten wir uns vor den schönen Worten; vor den Besseren Welten, wie sie von den Worten geschaffen werden. Unsere Epoche versinkt in einem Exzess an Worten. Es gibt kein anderes Gelobtes Land als jenes, das der Mensch in sich selbst finden kann." Und während er dies sagte, dachte Esteban an Ogé, der so häufig einen Satz seines Meisters Martínez de Pasqually zitierte: Das menschliche Wesen wird alleine von der Entfaltung der göttlichen Fähigkeiten erleuchtet, die in ihm auf Grund des Vorherrschens der Materie noch schlafen ... ${ }^{6}$
\end{abstract}

In den Sätzen des Intellektuellen verbirgt sich die ganze Enttäuschung über das Scheitern der Revolution und ein Misstrauen, was jede weitere angeht, die noch folgen könnte. Da muss man angesichts der kubanischen, welche den Hintergrund für diese Aussagen im Roman liefert, einmal tief durchatmen. Unübersehbar fügt Carpentier hier eine Anspielung auf Diogenes ein, wobei die Laternen am helllichten Tag freilich selbst nicht das „Siècle des Lumières“ zu erleuchten vermögen. Wenn Diogenes mit der Laterne in der Hand bei Tage vergeblich nach dem edlen Menschen suchte, so konnte ihn auch der Kubaner Esteban nicht in den dunklen Zeiten der Revolution finden. Die Ironie des kubanischen Autors ist an dieser Stelle mit Händen zu greifen und auch seine Skepsis gegenüber all den schönen Worten, welche Revolutionen begleiten. Dies tat gleichwohl dem Bekenntnis des Autors zur Kubanischen Revolution keinen Abbruch.

Erfahrung hat zu Estebans Enttäuschung geführt, der seine Ideale nicht mehr verwirklichen zu können glaubt. Gleichzeitig ist er nicht bereit, gänzlich auf ein politisches Ideal zu verzichten. Die Haitianische Revolution wird in derlei Passagen im Kontext einer Geschichte der Menschheit gedacht, die sich durch Revolutionen fortbewege und letztlich keine andere Möglichkeit habe, als sich auf diesem Wege weiter zu schleppen und weiter zu entwickeln. Ob die nächste Revolution die richtige, die gute sein wird? Alejo Carpentier wird nach der kubanischen zumindest so tun, als wäre sie es für ihn gewesen. Deshalb wird er auch heute noch im revolutionären Kuba sehr geachtet.

Und doch darf man vermuten, dass vieles von dem, was er Esteban hier in den Mund legte, auch später noch von ihm selbst über Revolution und Revolutionen hätte gesagt werden können. Die Haitianische Revolution jedenfalls bleibt hier anders als bei Victor Hugo, den Sie bitte nicht mit Victor Hugues verwechseln! kein Aufstand am Rande der Welt, sondern ein Ereignis von welthistorischem

6 Carpentier, Alejo: El siglo de las luces, S. 253. 
Rang: Ein Paradigmenwechsel hat unverkennbar stattgefunden. Mit Victor Hugo stimmt Alejo Carpentier jedoch zumindest in zwei Punkten überein: Erstens, dass das, was sich in der Karibik ereignete, nicht ohne die Philosophen des Jahrhunderts der Aufklärung hätte geschehen können, versuchten diese doch, ihre Laternen in die dunkelsten Winkel zu tragen und alles mit Hilfe der menschlichen Vernunft auszuleuchten. Und dass dies zweitens ein Teil jenes Problems darstellt, insofern allzu viele schöne Worte letztlich das zerstören, was an menschlichen Idealen tatsächlich und in der Realität verwirklicht werden kann. Wo Victor Hugo seinem Erzähler und seinen Figuren wütend und wutschnaubend eine Verdammung der Französischen Revolution, vor allem aber ihrer Vordenker in den Mund legte, da ist auch Alejo Carpentier - freilich aus ganz anderen Gründen - kritisch gegenüber jenem Jahrhundert der Aufklärung, das seinem Roman den so hintergründigen Titel gab. Denn er sieht die Geschichte der Aufklärung nicht als einen linearen, zu Fortschritt und Freiheit führenden menschheitsgeschichtlichen Prozess, sondern als eine Dialektik der Aufklärung, wie sie Max Horkheimer und Theodor W. Adorno unter dem Eindruck der Katastrophen des Zweiten Weltkriegs beschrieben und entfalteten. ${ }^{7}$

Wie aber wurde bei Alejo Carpentier die Haitianische Revolution im Roman dargestellt? Zur Beantwortung dieser Frage könnte man auf manche Passage aus El siglo de las luces zurückgreifen; doch besser und interessanter noch ist es, dazu El reino de este mundo aufzuschlagen, in dem sich der kubanische Schriftsteller und Literaturtheoretiker erstmals bei Reflexion und Verwirklichung seiner neuen Ästhetik des „real maravilloso“ zeigte.

In seinem 1949 erschienenen Roman Das Reich von dieser Welt griff Carpentier auf manche Artikel zurück, die er zuvor zur Lage der Schwarzen in der Karibik verfasst hatte. Er entwickelte seine neuartige Ästhetik des „real maravilloso“ welche es vom späteren „realismo mágico“ klar zu trennen gilt - als einen Bruch mit der Ästhetik des Surrealismus, der im Sinne der historischen Avantgarden seinerseits eine Ästhetik des Bruchs mit vielen vorherigen literarischen und ästhetischen Konventionen gewesen war. ${ }^{8}$ Der Kubaner distanzierte sich zugleich vom sozialistischen Realismus sowie vom Existentialismus Sartre'scher Prägung und versuchte, seine Perspektivik von den Amerikas - genauer: der Karibik - aus $\mathrm{zu}$ finden.

7 Vgl. Horkheimer, Max / Adorno, Theodor W.: Dialektik der Aufklärung. Philosophische Fragmente. Mit einem Nachwort von Jürgen Habermas. Frankfurt am Main: Fischer 1986.

8 Vgl. zum Surrealismus im Kontext der historischen Avantgarden Ette, Ottmar: Von den historischen Avantgarden bis nach der Postmoderne, S. 336-378. 
Konkret geht es in El reino de este mundo um die Situation der Schwarzen in der Karibik während der Epoche der Französischen Revolution und der nachfolgenden napoleonischen Ära, also genau um jenen Zeitraum, mit dem wir uns rund um die Haitianische Revolution ausführlich beschäftigt haben. Den Impuls für deren Deutung erhielt Carpentier während seiner bereits erwähnten HaitiReise, die ihn zutiefst mit jener Welt transkultureller schwarzer Kulturen vertraut machte, mit der sich auf Kuba der einflussreiche Anthropologe Fernando Ortiz beschäftigte. Im Zentrum des Romans stehen Geschehnisse, die sich mit Hilfe abendländischer Vernunft nicht aufklären lassen, die aber feste Bestandteile einer Realität bilden, in der ,Wunder‘ nichts anderes als Wirklichkeit sind. Daher rührt auch die Bezeichnung seiner Ästhetik als „real maravilloso“. Der Mensch, aber auch die tropische Natur entziehen sich einer vereinheitlichenden Logik abendländischen Zuschnitts und entwickeln ihre spezifischen Eigen-Logiken. Aus deren Perspektivik erscheinen die fundamentalen Defizite, aber auch die Verlogenheiten westlicher Zivilisation sehr deutlich.

Auf diese Weise zieht Alejo Carpentier die ästhetischen Konsequenzen aus seiner früh schon - noch vor Erscheinen seines Debütromans - gemachten Feststellung, dass die Probleme und Herausforderungen in den Amerikas grundverschieden von denen Europas seien und nicht mit den vorherrschenden Mitteln europäischen Denkens behandelt werden könnten. Er wusste sich damit in Übereinstimmung mit seinem Landsmann José Martí, der in den achtziger und neunziger Jahren des 19. Jahrhunderts die Vorherrschaft europäischer Ideen bestritt und nachdrücklich auf die Entfaltung eigener Denkansätze drängte, mit denen wir uns zu einem späteren Zeitpunkt in dieser Vorlesung beschäftigen werden. Zugleich hatte José Martí bereits zu diesem frühen Zeitpunkt den Fassadencharakter einer zutiefst korrupten und auf die Macht der Trusts setzenden Demokratie in den USA erkannt und vor der Ausbreitung einer US-amerikanischen Weltmacht und Wirtschaftslogik eindringlich gewarnt. Auch dieser Aspekt ging zweifellos in Alejo Carpentiers Vision der Karibik mit ein.

Beschäftigen wir uns also in der gegebenen Kürze mit jenem Text, der Carpentiers internationalen Durchbruch als Schriftsteller bedeutete und zugleich programmatisch die lateinamerikanischen Literaturen veränderte! Denn El reino de este mundo, der zweite Roman des kubanischen Autors, wäre ohne die Entwicklungen des 19. Jahrhunderts in ganz Lateinamerika nicht denkbar gewesen und wird uns Möglichkeiten und Denkweisen aufzeigen, die bei unserem Durchgang durch das - grob gesagt - Jahrhundert der Romantik von großem Nutzen sein werden. Denn seine „Chronik des Wunderbaren“ fußt auf den ästhetischen Entwicklungen des 19. Jahrhunderts.

Denn was Carpentier in seinem Roman behandelt, ist ein bislang viel $\mathrm{zu}$ wenig beleuchteter Weg Lateinamerikas aus dem Jahrhundert der Aufklärung in 
das 19. Jahrhundert, wofür die Geschicke von Saint-Domingue alias Haiti stellvertretend stehen mögen. Ich möchte Sie hier nicht mit der Geschichte des schwarzen Sklaven Ti Noël traktieren oder Ihnen langatmig einzelne Episoden aus dem Leben einer anderen faszinierenden Figur Carpentiers, des mit schwarzen Zauber- und Wunderkünsten vertrauten Mackandal, nacherzählen. Was bei Victor Hugo als schwarzer Zauber oder Aberglaube erschien und negativ gebrandmarkt wurde, wird bei Alejo Carpentier aus dem Kernbestand afrikanischer Kulte abgeleitet und vieldeutig in die eigene erzählte Geschichte oder - im Sinne des kubanischen Autors - „Chronik“ überführt.

Die Ihnen schon bekannten historischen Gestalten Boukman und Biassou erscheinen in El reino de este mundo 1791 auf der Bühne der Geschichte. Doch die Haitianische Revolution führt vorwärts in die Vergangenheit, etablieren doch maßgebliche Figuren wie König Henri Christophe wieder feudalistische Verhältnisse und Ausbeutungsformen, die jenen der weißen Kolonialherren in nichts nachstehen. Denn der ursprünglich aus Grenada stammende Henri Christophe, der früh schon gegen die Franzosen gekämpft hatte, schwelgt in seinem Luxuspalast Sanssouci in unermesslichem Reichtum und übt seine Macht mit allen Mitteln einer Despotie aus. Doch zahlreiche Wunder geschehen, Trommeln ertönen und überall erheben sich die Schwarzen wiederum gegen ihren neuen Herrscher, dessen Palast sie in Brand setzen. Die Gewalt in Haiti hält an.

Sicherlich, die Geschichte geht im Reich von dieser Welt nicht gut aus: Ti Noël muss auch die Despotie der Mulatten erleben und verzweifelt an der Conditio humana, den Bedingungen menschlichen Lebens auf diesem Planeten. Doch die Größe des Menschen besteht in seinem Handeln, Hoffen und Lieben inmitten seines Elends; und Ti Noël stirbt am Ende nicht eines natürlichen Todes, sondern verwandelt sich in einen Geier, in ein Tier, dessen Spuren sich im Urwald verlieren. Er verkörpert so jene wunderbare Wirklichkeit, wie sie Alejo Carpentier nicht nur für Haiti oder die Karibik, sondern für ganz Lateinamerika als wesenhaft postulierte.

Ich möchte Ihnen gerne die entscheidende Passage aus dem Schlusskapitel des ersten von vier Teilen zeigen und daran vorführen, wie es dem kubanischen Autor gelingt, nicht nur das Wissen der Schwarzen dem der Weißen entgegenzustellen, sondern zugleich auch dieses Wissen der schwarzen Bevölkerungsmehrheit im Vorfeld der haitianischen Revolution in seiner wunderbaren Wirklichkeit vor Augen zu führen. Damit erweitert er den Wirklichkeitsbegriff des Romans. Denn die Integration zusätzlicher, weiterer Logiken läuft in aller Regel auf eine Weitung und Erweiterung von Weltsichten hinaus. ${ }^{9}$

9 Vgl. hierzu Ette, Ottmar: Weiter denken. Viellogisches denken / viellogisches Denken und die Wege zu einer Epistemologie der Erweiterung. In: Romanistische Zeitschrift für Literaturgeschichte / Cahiers d'Histoire des Littératures Romanes (Heidelberg) XL, 1-4 (2016), S. 331-355. 
Kurz zum Inhalt des Romans: Der aller Zauber- und Verwandlungskünste in den schwarzen Kulturen kundige Sklave Mackandal ist gefangen genommen und zum Tode verurteilt worden. Er soll baldmöglichst hingerichtet werden. So wird er auf einen großen Platz in jener Stadt geführt, die heute den Namen Cap Haïtien, damals Cap Français trug. Dort soll er öffentlich vor den Augen der versammelten Weißen und vor allem ihrer Sklaven verbrannt werden. Der Henker steht bereit, die Regimenter sind angetreten. Alles kündet von der Macht und Gewalt der Weißen mitsamt ihrer vernichtenden Logik:

Plötzlich schlossen sich gleichzeitig alle zuvor aufgespannten Fächer. Hinter den Militärtrommeln machte sich ein tiefes Schweigen breit. Mit einer gestreiften Hose um seine Lenden, bedeckt mit Seilen und Knoten, mit frischen, schmerzhaften Wunden übersät, rückte Mackandal zum Mittelpunkt des Platzes vor. Die Sklavenherren befragten mit einem Blick die Gesichter ihrer Sklaven. Aber die Schwarzen zeigten eine boshafte Indifferenz. Was wussten die Weißen schon von den Dingen der Schwarzen? In seinen zyklischen Metamorphosen hatte sich Mackandal viele Male schon in die arkane Welt der Insekten vertieft, wobei er das Fehlen eines menschlichen Armes durch den Besitz vieler Beine, vier Kneifern sowie langer Antennen ausglich. Er war schon eine Fliege gewesen, ein Tausendfüßler, ein Nachtfalter, eine Termite, eine Tarantel, ein Marienkäfer und sogar ein Taca-Taca oder Tagüinchen mit großen, grün fluoreszierenden Leuchten. Im entscheidenden Augenblick würden die Fesseln des Mandinga, von einem Körper befreit, den sie nicht länger festhalten konnten, nachgeben und noch die Umrisse eines Menschen aus Luft nachzeichnen, bevor sie an den Pfosten herunterbaumeln würden. Und Mackandal, in einen schwirrenden Moskito verwandelt, würde sich gar auf den Dreispitz des Anführers der Truppen setzen, um sich am Unwissen der Weißen zu belustigen. Denn das war es, was die weißen Herren nicht wussten; deshalb hatten sie soviel Geld verschwendet, um jenes unnütze Spektakel $\mathrm{zu}$ organisieren, das ihre totale Impotenz demonstrierte, um gegen einen Menschen anzukämpfen, den die großen Loas verschwinden ließen.

Mackandal stand schon mit dem Rücken am Pfahl seiner Qualen. Der Henker hatte einen Gurt mit den Zangen gepackt. Der Gouverneur wiederholte eine Geste, die er am Vorabend vor dem Spiegel geprobt hatte, zog sein höfisches Schwert aus der Scheide und erteilte Befehl, den Richterspruch auszuführen. Das Feuer begann, bis zum Einarmigen empor zu lecken, und züngelte an dessen Beine hoch. In diesem Augenblick hob Mackandal seinen Stumpf, den sie nicht hatten festzurren können, in einer drohenden Geste, die zwar klein, aber deshalb nicht weniger schrecklich war, und stieß unbekannte Flüche aus, wobei er seinen Oberkörper ruckartig nach vorne warf. Seine Fesseln fielen, und der Körper des Schwarzen hob sich in die Lüfte und flog über die Köpfe, bevor er sich in den schwarzen Wellen der Masse von Sklaven verlor. Ein einziger Schrei erfüllte den ganzen Platz.

- Mackandal sauvé, Mackandal gerettet!

Und alles war Durcheinander und Lärm. ${ }^{10}$

10 Carpentier, Alejo: El reino de este mundo. Introducción Federico Acevedo. San Juan PR: EDUPR 1994, S. $39 \mathrm{f}$. 
In dieser Passage wird deutlich, wie in dem 1949 veröffentlichten kleinen, aber literargeschichtlich bedeutenden Roman des kubanischen Autors die schwarzen Kulturen und deren kulturelle Ausdrucks- und Vorstellungswelten nicht länger dämonisiert werden, sondern zu einem essentiellen Bestandteil eines Wirklichkeitskonzepts avancieren, das die ,wunderbaren“ Elemente ganz selbstverständlich als Tatsachen in sich aufnimmt. Wir wissen ja, dass auch heute noch der Bereich der ,Wunder' in und bei der Wissenschaft hochumstritten und definitionsbedürftig ist, ${ }^{11}$ dass es also im Reich abendländischer Rationalität keineswegs einen Konsens bezüglich der Grenzen zwischen dem Rationalen und sogenannten Wundern gibt. In meinem eigenen Studium habe ich mit großer Freude an der Universität Freiburg den parapsychologischen Vorlesungen von Hans Bender gelauscht, der von vielen wissenschaftlich erforschten Phänomenen sprach, die mühelos in Alejo Carpentiers Konzept des „real maravilloso“ gepasst hätten, von wiederkehrenden ,Erscheinungen` bis hin zu den von ihm untersuchten Blutwundern.

In dieser Szene aus El reino de este mundo ist das, was ,die“ Wirklichkeit darstellt oder ausmacht, in seinen rationalen Grenzen unsicher geworden: Das spüren sogar die Weißen, die versuchen, in den Augen und Gesichtern ihrer schwarzen Sklaven zu lesen. Und in der Tat führt die Verbrennung Mackandals vor aller Augen nur vor, was zumindest die Schwarzen seit geraumer Zeit wussten und nun auf dem Marktplatz öffentlich vorgeführt bekommen. Es handelt sich um die Szene der wunderbaren Errettung Mackandals, der unverständliche - zumindest für die Weißen unverständliche - Worte ausstößt und dann dem Feuer entrinnt dank seiner bei allen Sklaven bekannten Fähigkeit, sich in verschiedenste Insekten zu verwandeln und sich seiner Hinrichtung durch Metamorphose zu entziehen. Der Schrei, der den Platz erfüllt, kündet von der realen Wirklichkeit dieses Wissens, kündet von der Präsenz schwarzer Kulte und Vorstellungen, welche die Sklaven etwa aus dem afrikanischen Benin mitbrachten und die wir gemeinhin als Voodoo kennen. Und dass Voodoo-Kulte nicht einfach schwarzer Aberglaube sind, haben wissenschaftliche Untersuchungen seit langen Jahrzehnten belegt. ${ }^{12}$

Damit kommt etwas in den zeitgenössischen Roman Hispanoamerikas, das für den Surrealisten-Freund und späteren Surrealisten-Kritiker Alejo Carpentier gleichsam in der kubanischen und karibischen Atmosphäre lag und nur von ihm

11 Vgl. hierzu Daston, Lorraine: Wunder, Beweise und Tatsachen. Zur Geschichte der Rationalität. Aus dem Englischen von Gerhard Herrgott, Christa Krüger und Susanne Scharnowski. Frankfurt am Main: Fischer Taschenbuch 2001.

12 Vgl. etwa Rigaud, Milo: La Tradition Voudoo et le Vaudoo haïtien. Photographies de Odette Menesson-Rigaud. Paris: Editions Niclaus 1952. 
aufgenommen werden musste. Es waren gerade die vierziger Jahre des 20. Jahrhunderts, in denen sich mit zum Teil erheblicher Breitenwirkung neue Konzepte zum Verständnis der komplexen kulturellen Entwicklungen im Bereich der Karibik entfalteten. Die Karibik wurde zu so etwas wie einem Think-Tank für kulturelle wie literarische Theoriekonzepte weltweit - und dies gleich für mehrere Jahrzehnte.

Denn das Jahr 1940 bot mit einem Konzept aus der Feder des kubanischen Anthropologen Fernando Ortiz einen wichtigen Beitrag zur anthropologischen, weit darüber hinausreichend aber auch zur kulturtheoretischen Diskussion, die zum damaligen Zeitpunkt in den vierziger Jahren weltweit noch um Fragen der Akkulturation kreiste. Alejo Carpentier war sich als „poeta doctus“ dieser für ihn unüberhörbaren Diskussionen und insbesondere auch des Beitrages seines Landsmannes Fernando Ortiz bestens bewusst, als er gegen Ende der vierziger Jahre seinen Roman El reino de este mundo verfasste. Da Ortiz‘ Konzept für unsere Vorlesung von großer Wichtigkeit ist, möchte ich ihm einen gewissen Raum im Rahmen unseres nicht allzu langen Exkurses geben.

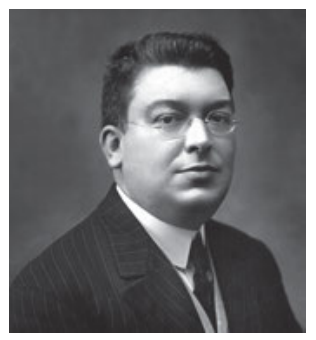

Abb. 26: Fernando Ortiz (Havanna, Kuba, 1881 - ebenda, 1969).

Der kubanische Anthropologe und Kulturtheoretiker Fernando Ortiz bildete einen wichtigen und interessanten Übergangstypus zwischen dem Schriftsteller und dem Experten als Sprachrohr einer nationalen oder kontinentalen Verständigung über die eigenen Werte der Nation sowie der iberischen Welt Amerikas. Ortiz' erste Publikationen reichen noch ins 19. Jahrhundert zurück. Er steht einerseits als Figur gleichsam zwischen dem Kubaner José Martí, den er verehrte, und dem Uruguayer José Enrique Rodó, dem Schriftsteller und Intellektuellen, der einen Gesamtentwurf Lateinamerikas vor dem Hintergrund einer literarisch modellierten Kulturkonzeption entwarf. Andererseits verkörpert er einen Intellektuellen heutigen Typs, eines lateinamerikanischen Intellektuellen, der im Sinne etwa Néstor García Canclinis oder Jesús Martín-Barberos ein Experte im akademischen (oder auch literarischen) Feld zu sein hat. Mit Rodó und Martí werden wir uns im letzten Teil unserer Vorlesung noch ausführlich beschäftigen.

Bei García Canclini oder Martín-Barbero handelt es sich um Akademiker, die sich als Anthropologen oder Kommunikationswissenschaftler einen Namen machten, bevor sie in die Arena der breiteren Öffentlichkeit als sinnvermittelnde 
und sinnstiftende Intellektuelle traten. Der 1881 in La Habana geborene und 1969 ebendort verstorbene Fernando Ortiz kommt diesen aktuellen lateinamerikanischen Intellektuellen bereits sehr nahe und repräsentiert einen wichtigen und weitgehend übersehenen Übergang hin zu einer wesentlich von Experten geprägten Diskussions-Kultur, in welcher das im akademischen Feld erworbene Prestige eine wichtige, vielleicht entscheidende Rolle spielt. Denn Fernando Ortiz ist von Hause aus Anthropologe sowie Ethnologe und bringt seine Erfahrungen bei der Untersuchung schwarzer Kulturen auf Kuba in seine Theoriebildungen ganz wesentlich mit ein. Alejo Carpentiers Rückgriff auf die Veröffentlichungen seines Landsmannes war folglich keineswegs zufällig.

Wenn wir uns relativ ausführlich mit einigen Biographemen von Ortiz beschäftigen, dann deshalb, weil ich gerne möchte, dass Sie verstehen, wie schwierig allein schon in der Wissenschaft der Weg heraus aus rassistischen Vorurteilen war, um ein adäquates Bild schwarzer Kulturen zu entwickeln. Sie sollen auch nachvollziehen können, dass Ortiz' Laufbahn als wissenschaftlicher Vorläufer einer kritischen Bewegung, die noch in unseren Tagen unter dem Motto „Black Lives Matter“ mit großen Schwierigkeiten versucht, Menschen von ihrem rassistischen Denken zu befreien, auf eine höchst charakteristische Art weder geradlinig noch stringent aufklärerisch verlaufen konnte. Denn es liegt mir am Herzen, dass Sie die historischen Prozesse nachvollziehbar begreifen, in denen sich gerade mit Blick auf die schwarzen Kulturen im 19. Jahrhundert das Rassedenken und der Rassismus verdichteten und wie schwer es war, sich all dieser Dinge bewusst zu werden. Und wie sehr gerade die Literaturen der Welt in diesem Zeitraum Visionen entwickelten, welche derartige Verstrickungen beleuchteten. Ich hoffe, dass Sie vor diesem Hintergrund noch viel genauer verstehen, welch innovativen Potentiale etwa ein Text wie Heinrich von Kleists Die Verlobung in St. Domingo zu seiner Zeit besaß.

Dass der Lebens- und Forschungsweg des kubanischen Anthropologen nicht so geradlinig verlief, wie wir uns dies vielleicht wünschen würden, lag weniger in der Tatsache begründet, dass der junge Ortiz als Sohn eines spanischen Vaters einige Jahre auf der Balearen-Insel Menorca verbrachte. Dort ließ er als Fünfzehnjähriger im Jahre 1895 - als auf Kuba gerade der entscheidende, von Martí geplante Unabhängigkeitskrieg losbrach - sein erstes Buch über einige folkloristische Aspekte seiner Wahlheimat im menorquinischen Dialekt erscheinen. Denn sein Weg führte ihn von deutlich rassistisch geprägten und an seinem Lehrmeister Cesare Lombroso ${ }^{13}$ ausgerichteten philologischen Positionen, die noch

13 Vgl. hierzu die Überlegungen zu Lombroso in der schönen und perspektivreichen Arbeit von Lenz, Markus Alexander: Genie und Blut. Rassedenken in der italienischen Philologie des neunzehnten Jahrhunderts. Paderborn: Wilhelm Fink Verlag 2014, S. 297-302. 
von großem Unverständnis für „die kriminellen Schwarzen“ geprägt waren, hin $\mathrm{zu}$ sehr viel offeneren Überzeugungen, welche ihn $\mathrm{zu}$ einem der wesentlichen ,Entdecker“ der Präsenz afrikanischer Kulturen in der Karibik und zu den Kulturentwicklungen im afrokaribischen Raume machten. Dabei scheint es mir keineswegs nebensächlich zu sein, dass Ortiz sein großes und umfassendes Gesamtwerk gleichsam mit einer translingualen Insel-Erfahrung begann. Denn er sollte diese Sensibilität gegenüber anderen Sprachen und Ausdrucksformen gerade in seinen detailreichen Studien afroamerikanischer und afrokaribischer Kulturen wissenschaftlich schon bald unter Beweis stellen.

Nach Kuba zurückgekehrt nahm er in Havanna ein Studium der Jurisprudenz auf, das er dann in Barcelona abschloss und dem er seine Promotion in Madrid im selben Fach folgen ließ. Sein Fokus wird in der Folge zunächst von eher kriminalistisch, also an Verbrechen ausgerichteten Untersuchungen her auf sozialen ,Randgruppen' liegen, wobei ihm gerade die kriminologische und in einem philologischen Rassedenken verankerte Schule Cesare Lombrosos ${ }^{14}$ entscheidende Anstöße vermittelte. Sein erstes Werk in Buchform ist 1906 Los negros brujos, in welchem sich diese methodologische Ausrichtung unverkennbar zeigt. Er erforscht die hohe Kriminalitätsrate von Schwarzen in Kuba aus einer damals noch rassegeleiteten Perspektive. Durch diese Studien kommt er in direkten Kontakt mit Problemen und Fragestellungen der dortigen marginalisierten schwarzen Bevölkerung und verwendet - wohl als erster überhaupt - die Vokabel „afrocubano“.

Bald schon wird er Teil des Lehrkörpers der Universität von Havanna, wo er in der Folge verschiedene Lehrstühle übernimmt und seine Lehrtätigkeit ausweitet. Ortiz wird zu einem anerkannten Maestro: Hier bildete er bereits einen Schülerkreis um sich, wobei sich verschiedene Generationen seiner Schülerinnen und Schüler ausmachen lassen. So zählen die Kulturanthropologin Lydia Cabrera auf der einen, der Erfinder der „novela-testimonio“ Miguel Barnet auf der anderen Seite bald zu seinen berühmtesten Schülern: Die eine wird später ins US-amerikanische Exil gehen, der andere zu einem von der Kubanischen Revolution verehrten Schriftsteller werden. Miguel Barnet übernahm später auch die Leitung der durchaus einflussreichen Fundación Fernando Ortiz in Havanna.

Von größter Wichtigkeit für den weiteren Werdegang des Fernando Ortiz und seine große Wirkung auf das Denken der Kubaner über sich selbst ist die Tatsache, dass er schon früh begann, durch die Mitarbeit und Mitbegründung von Zeitschriften - zum Teil in Zusammenarbeit mit Alejo Carpentier - eine wichtige Rolle im

14 Vgl. Melis, Antonio: Fernando Ortiz e la Cultura Italiana. In: Ideologie. Quaderni di storia contemporanea (Firenze) 5 - 6 (1968), S. 197-206. 
intellektuellen Feld Kubas zu übernehmen. Dem Anthropologen kam eine strategisch ungeheuer wichtige Position und Funktion innerhalb der auf Havanna zentrierten Intelligenzija, dieses kubanischen „champ intellectuel“ im Sinne Pierre Bourdieus $^{15} \mathrm{zu}$. Grundlegend etwa war seine Revista Bimestre cubana, aber auch eine Vielzahl weiterer Periodika, welche seine überragende Rolle als Intellektueller und nicht mehr nur als Gelehrter dokumentieren. Im Laufe dieser fachlichen wie intellektuellen Arbeiten löste sich Ortiz von seinem anfänglichen Rassedenken und konnte $\mathrm{zu}$ jenem großen Erforscher afrokubanischer und afrokaribischer Kulturen werden, als der er mit Recht in die Geschichte eingegangen ist.

Seine kriminologische und positivistische Ausrichtung wurden folglich bald durch eine offenere, breitere, vor allem kulturanthropologisch fokussierte Denkund Forschungsweise ersetzt, die sich stets der politischen Tragweite des eigenen Forschens bewusst war. Wir sehen bei Fernando Ortiz einen Mechanismus am Werk, wie er den ,klassischen` Intellektuellen auszeichnet: Er führt die Übertragung eines auf einem wissenschaftlichen Teilfeld erworbenen symbolischen Kapitals auf das intellektuelle Feld im Allgemeinen vor, wo eine gewisse Meinungsführerschaft dann künftig immer wieder auch für direkte Einflussnahme im politischen Feld der Insel genutzt werden kann. Bereits seit 1917 war er auch in spezifisch politischen Funktionen auf der Insel tätig.

Fernando Ortiz erstaunt uns noch heute durch jene Mischung aus Spezialisten-Wissen - das er etwa in seinen lexikologischen Studien vorführte - und einer beeindruckenden Allgemeinbildung, die freilich vorrangig literarisch geprägt war und durch welche er Kontakte $\mathrm{zu}$ vielen großen Autor*innen und Künstler^innen seiner Zeit besaß. Im politischen Bereich wird seine Position bezüglich der bestehenden wirtschaftlichen und sozialen Verhältnisse immer kritischer: Bald schon gehört er jener politischen und intellektuellen Avantgarde Kubas an, die sich seit 1923 bildete $^{16}$ und die unter dem Namen „Grupo minorista“ berühmt wurde. Der „Minoristengruppe“ gehörten Schriftsteller und Intellektuelle wie Alejo Carpentier oder Rubén Martínez Villena an. Seine letzte kriminologische Arbeit bildete 1926 der Código criminal cubano, danach schlug Ortiz dieses Kapitel seiner Methodologie und Theoriebildung endgültig zu. Doch dieser lange Zeitraum eines Vierteljahrhunderts zeigt, wie schwer und anspruchsvoll es war, sich von den rassistischen Vorurteilen gegenüber der schwarzen Bevölkerung in der Wissenschaft zu befreien und neue kreative Perspektiven zu eröffnen.

15 Vgl. zur Feldtheorie des französischen Soziologen Jurt, Joseph (Hg.): Absolute Pierre Bourdieu. Freiburg i.Br.: Orange-Press 2003; sowie (ders.): Bourdieu. Stuttgart: Philipp Reclam jun. 2008.

16 Vgl. zu den historischen Avantgarden und insbesondere den zwanziger Jahren Ette, Ottmar: Von den historischen Avantgarden bis nach der Postmoderne, S. 49-398. 
Seine mit Alejo Carpentier vergleichbar klare Frontstellung gegen die blutige Diktatur Gerardo Machados, gegen den er ein Manifest verfasste, zwang ihn 1930 ins Exil in die USA, wo er drei Jahre verbringen und seine wissenschaftlichen Kenntnisse vor seiner Rückkehr nach Kuba 1933 weiter stärken sollte. 1937 gründete und leitete er die Sociedad de Estudios Afrocubanos, die sich nicht zuletzt auch um eine stärkere gesellschaftliche Integration der schwarzen Bevölkerung in Kuba bemühte - wenige Jahre vor Veröffentlichung seines bis heute vielleicht durchschlagendsten und sicherlich auch aktuellsten Buches, dem 1940 erstmals publizierten Contrapunteo cubano del tabaco y el azúcar.

In den folgenden Jahren schließen sich seinen politischen Aktivitäten, die auch antifaschistische Aktionen beinhalten, eine weite internationale Vortragstätigkeit sowie die ausgreifende Beschäftigung mit den verschiedensten Lebensbereichen nicht nur der schwarzen gesellschaftlichen Gruppen an, wobei er allerdings der afrokubanischen Kultur stets sein Hauptaugenmerk widmen sollte. Doch es gibt in seiner Bibliographie auch stark historisch ausgerichtete Studien etwa über Fray Bartolomé de Las Casas oder auch Alexander von Humboldt, den sogenannten „zweiten Entdecker Kubas“, wie Sie heute noch an einer Inschrift lesen können, die am Sockel des Denkmals vor dem Haupteingang der HumboldtUniversität von der kubanischen Gesandtschaft unmittelbar vor Ausbruch des Zweiten Weltkriegs angebracht wurde. Nicht von ungefähr stammt daher auch der Beiname von Fernando Ortiz als „dritter Entdecker Kubas“, war er es doch gewesen, der die entscheidenden Anstöße für eine wissenschaftliche, aber auch gesellschaftliche Einbeziehung schwarzer Kulturen und Gruppen in die Gesamtgesellschaft forderte, vorantrieb und förderte.

Es schlossen sich viele internationale Auftritte, Ehrungen und Auszeichnungen, aber auch weitere Forschungen und Bücher an. Fernando Ortiz wurde von der Kubanischen Revolution als Forscher und Gelehrter, wenn auch weniger als Intellektueller einbezogen. 1964, also fünf Jahre nach deren Triumph, erschien seine bedeutend erweiterte Ausgabe des ursprünglich 1940 veröffentlichten Contrapunteo, mit dem wir uns in der Folge näher beschäftigen wollen. Vergessen wir rückblickend aber nicht, dass ein Bernardin de Saint-Pierre, ein Heinrich von Kleist oder ein Victor Hugo nicht über die Studien und Einsichten eines Fernando Ortiz verfügen konnten und ihr Bild der Schwarzen noch anders geartet sein musste.

Als die erste Ausgabe des Contrapunteo cubano del tabaco y el azúcar 1940 erschien, hatte Fernando Ortiz längst seine Positionen hinter sich gelassen, die ihn im Umkreis kriminologischer Methodologien sehr wohl zu rassistischen Ansichten und Einsichten geführt hatten, denen zufolge die Schwarzen auf dem Weg zur Zivilisation ein Hemmnis und eine Barriere für Kuba darstellten. Ich erwähne dies nicht, um Fernando Ortiz nachträglich zu belasten, sondern um 
Herkunft, Bewegung und Zukunft seines Denkens hervortreten zu lassen. Denn es gibt Wissenschaften, die sich erst auf der Negativfolie bisheriger Untersuchungen in einem beständigen Abgrenzungsprozess, in einem zähen Ringen zu entwickeln vermögen - und hierzu zählt zweifellos die anthropologische Untersuchung afrokubanischer Kulturen durch Ortiz. Die kulturanthropologischen Studien des Kubaners wurden erst möglich vor dem Hintergrund einer Auseinandersetzung, in welcher Fernando Ortiz zum Verfasser auch des ersten lateinamerikanischen Handbuchs für Fingerabdrücke wurde - und auch diesen Hinweis auf die Fingerabdrücke, deren technische Verwendung übrigens aus der britischen Kolonialherrschaft stammt, will ich nicht aus anekdotischen Gründen erwähnen.

Aufschlussreich aber ist die Tatsache, dass sich Fernando Ortiz gerade gegen Ende der dreißiger und zu Beginn der vierziger Jahre besonders intensiv mit Denken und Wirken José Martís auseinandersetzte, jenem herausragenden kubanischen Schriftsteller, Dichter und Revolutionär. ${ }^{17}$ Wir werden uns noch mit Martís literarischem Einfluss auf die Literaturen und vor allem die Dichtkunst seiner Zeit beschäftigen. Doch können wir nun seine Bedeutung auf einem ganz anderen Gebiet konstatieren, einem Gebiet, das jedoch nicht auf Anthropologie, Kultur oder Literatur beschränkt bleibt, sondern in wesentlicher Weise an Fragen einer erst noch auszubildenden nationalen Identitätssuche Kubas und damit allgemein an Fragen nationaler Identitätsfindung ausgerichtet ist.

Der Schöpfer des Contrapunteo cubano erreichte hier eine Dimension des Politischen, die sich nicht auf die Politik von Parteien beschränkt. Denn von einer solchen Politik, der er sich 1917 auch als Vertreter der Liberalen und sogar als Vizepräsident der Abgeordnetenkammer angeschlossen hatte, wandte er sich bereits 1926 wieder ab. Ortiz interessierte mehr das Politische als die Politik: Dies war das Feld, auf das er vor dem Hintergrund seiner wissenschaftlichen Studien einwirken konnte. Wir sollten uns freilich davor hüten, die Abkehr des Fernando Ortiz, der 1915 der Liberalen Partei Kubas beigetreten war, von der Parteienpolitik im Sinne der Kubanischen Revolution, die den Anthropologen für sich reklamierte, so zu interpretieren, als ob hier ein Linker, ja ein Sozialist grundlegende Kritik an einem Parteiensystem geäußert hätte, wie es mit der Kubanischen Revolution dann 1959 überwunden worden sei. Denn es fällt nicht schwer, im Leben des großen Kubaners neben antifaschistischen Aspekten auch andere zutage zu fördern, in denen sich eine durchaus ambivalente Haltung gegenüber rechten Diktaturen ausdrückt. Auch im politischen Spektrum blieb der kubanische Anthropologe eine schillernde Gestalt, die gerade in ihrer parteipolitischen Dimension und mehr

17 Vgl. Ette, Ottmar: José Martí. Teil I: Apostel - Dichter - Revolutionär. Eine Geschichte seiner Rezeption. Tübingen: Max Niemeyer Verlag (Reihe mimesis, Bd. 10) 1991. 
noch in ihrem Verständnis des Politischen einmal eine eingehendere kritische Auseinandersetzung verdient hätte.

In einem 1941 gehaltenen Vortrag hatte Fernando Ortiz über Martí und die Rassen gesprochen und dabei die enge Verbindung betont, die historisch und auch im Falle Kubas höchst konkret zwischen Kolonialismus und Rassismus bestand. In diesem Vortrag wurde auch deutlich, dass gerade José Martí für den kubanischen Kulturtheoretiker - wie übrigens auch für einen Alejo Carpentier - zu jener Stütze einer Befreiung von rassistischen Vorstellungen werden konnte, die es dann erlaubte, nicht nur die Untersuchung der schwarzen Kulturen um ihrer selbst willen anzugehen. Es ging für Ortiz längst nicht mehr darum, ein Problem gefährlich hoher Delinquenz zu lösen, sondern von einer ethisch fundierten Grundlage aus die nationale Identitätsproblematik anzugehen. Fernando Ortiz bekam mit José Martí gleichsam nationalen Boden unter die Füße einer Argumentation, die den schwarzen Kulturen einen nicht mehr nur marginalen, sondern zentralen Platz in der kubanischen Gesellschaft und der Gestaltung ihrer Zukunft anwies.

Insoweit ist in diesem Zusammenhang José Martís Rolle sicherlich höher einzuschätzen als jene Alexander von Humboldts, der gleichwohl für Ortiz eine wichtige Bezugsfigur blieb, die sich in ihrer Zeit bereits vehement gegen die Sklaverei eingesetzt hatte. Eine Vielzahl von Publikationen des Fernando Ortiz belegt, wie wichtig Humboldt - vor allem aber Martí - für sein Denken gerade in den vierziger und frühen fünfziger Jahren war, als er nach historischen Traditionslinien Ausschau hielt, welche seine Ansätze und Überlegungen stützen konnten. Doch kann ich dieser Traditionslinie an dieser Stelle nicht weiter nachgehen: Ich werde sie im gegebenen Zusammenhang bei unserer Besprechung von José Martí wieder aufnehmen. Ich möchte vielmehr versuchen, Ihre Aufmerksamkeit auf die spezifisch kulturtheoretischen, zugleich transarealen und transkontinentalen Aspekte des Denkens von Fernando Ortiz zu lenken, um aus den Traditionslinien des 19. Jahrhunderts heraus ein Konzept des 20. Jahrhunderts zu besprechen, das uns für die Analyse von Texten der Romantik zwischen zwei Welten noch gute Dienste leisten wird.

Die vehementen Angriffe des Fernando Ortiz gegen den seiner Ansicht nach grundlegend irrational gebrauchten Rassebegriff gehorchen seiner wissenschaftlichen Grundüberzeugung, die sich - wie Antonio Melis gezeigt hat ${ }^{18}$ - von der Sichtweise einer generellen Unterlegenheit schwarzer Kubaner in seinen frühen Schriften hin zur Betonung absoluter Gleichheit entwickelt hatte. Ortiz wusste

18 Vgl. Melis, Antonio: Fernando Ortiz y el mundo afrocubano: desde la criminología lombrosiana hasta el concepto de transculturación. In: Heydenreich, Titus (Hg.): Kuba. Geschichte Wirtschaft - Kultur. München: W. Fink Verlag 1987, S. 169-182. 
sich hier in Übereinstimmung mit Martí, der bereits im letzten Viertel des 19. Jahrhunderts den Rassebegriff und die ,Rassedenker‘ zurückgewiesen hatte und den Begriff „raza“ nur im kulturellen Sinne gebrauchte. Auch Ortiz dachte Differenz in seinen späteren Schriften ausschließlich als kulturelle.

Auf welche Weise der kubanische Anthropologe sie kulturell und historisch konzipierte, lässt sich mit Blick auf eine kulturelle Heterogenität vor allem in seinem 1940 erstmals erschienenem und 1963 beträchtlich erweiterten Contrapunteo cubano del tabaco y el azúcar nachweisen und bewundern. In diesem kunstvoll und literarisch gestalteten Wissenschaftsband wird gerade den zuvor nur marginal bedachten und gedachten Kulturen in ihrer Heterogenität die ganze Aufmerksamkeit zuteil.

Bis zur Einführung des Begriffs „Transkulturation“ durch den Kubaner hatte man in der Ethnologie und Anthropologie stets von „Akkulturation“ gesprochen und so - dies die Kritik von Ortiz - eine durchweg passive Übernahme der fremden durch die eigene, aber marginalisierte Kultur präsupponiert oder eben vorausgesetzt. Der zuvor dominante Begriff der Akkulturation legt nahe, dass die empfangende Kultur letztlich keine aktiven und kreativen Antworten auf den interkulturellen Austausch, der sich bei längerem Kulturkontakt vollzieht, zu geben vermag. Wir könnten hinzufügen, dass über einen sehr langen Zeitraum und fast bis in unsere Tage derartige Vorstellungen dominant blieben, wurde doch - um nur einige Beispiele zu nennen - von kulturellem Imperialismus, kultureller Penetration oder kultureller Dependenz gesprochen, ohne dabei auf die kreativen Kräfte der jeweils zum Objekt, nicht aber zum Subjekt gemachten Kulturen und Gesellschaften zu reflektieren. Wir müssen folglich aufpassen, die Eigen-Logiken von Kulturen selbst dann nicht zu unterschätzen, wenn sie unter massiver äußerer Einflussnahme stehen.

Fernando Ortiz führt an dieser Stelle ein weitestgehend neuartiges Denken ein. Der Begriff der Akkulturation als Beschreibung des Übergangs von einer Kultur zu einer dominanten anderen enthält nicht die transformativen Gestaltungskräfte, die für Fernando Ortiz von so großer Bedeutung sind. Bevor wir uns weiter über allgemeine Hintergründe und mögliche Konsequenzen des Begriffs „transculturación“ unterhalten, sollten wir aber den Schöpfer dieses Konzepts selbst zu Wort kommen und den Begriff definieren lassen. Er tat dies in einem Abschnitt, der dem eigentlichen Essay hinzugefügt wurde und in dem Ortiz im Titel auf das „Soziale Phänomen der ,Transkulturation“ und deren Wichtigkeit in Kuba“ einging:

Die Vokabel Transkulturation drückt nach unserem Verständnis besser die verschiedenen Phasen des Übergangsprozesses von einer Kultur in eine andere aus, weil dieser nicht darin besteht, eine verschiedene Kultur bloß zu erwerben, was im engeren Sinne der angloame- 
rikanische Ausdruck Aculturation meint, sondern dass dieser Prozess notwendig auch den Verlust oder die Entwurzelung einer vorherigen Kultur impliziert, so dass man von einer partiellen Dekulturation sprechen könnte, und überdies die nachfolgende Schöpfung neuer kultureller Phänomene beinhaltet, welche man als Neokulturation bezeichnen dürfte. In jeder Umarmung der Kulturen erfolgt, wie es sehr wohl die Schule von Malinowski sieht, genau das, was in der genetischen Verbindung von Individuen geschieht: Das entstandene Geschöpf enthält stets etwas von beiden am Zeugungsprozess Beteiligten, ist aber stets auch verschieden von jedem Einzelnen der beiden. Zusammengefasst ist der Prozess eine Transkulturation, und diese Vokabel umfasst alle Phasen dieser Parabel. ${ }^{19}$

Halten wir zunächst einmal fest, dass der Begriff „Transkulturation“ aus der kubanischen Forschung stammt und keineswegs - wie nicht selten zu lesen der englischsprachigen oder gar der deutschsprachigen Diskussion entsprungen ist. Nur allzu gerne hat man diesen spezifisch kubanischen Ursprung des Terms schlicht ausgeblendet und zum Teil bewusst verschwiegen, da man nicht verstand oder verstehen wollte, dass die Karibik eine höchst wichtige und produktive Lieferantin von Theoriekonzepten ist und man im sogenannten ,Westen“ lieber den eigenen Wissenschaften die Macht zuschrieb, Begriffe zur Beschreibung der ,Anderen' zu liefern.

Die uns von Fernando Ortiz in der obigen Passage vorgeschlagene Definition von Transkulturation zeigt verschiedene sich überlagernde Prozesse auf, die sich keineswegs nur als kultureller Gewinn, sondern eben auch als Verlust niederschlagen. Die sich aus diesem komplexen Prozess einschließlich „Dekulturation“ und „Neokulturation“ entwickelnde transkulturierte Kultur erweist sich dabei ihrerseits nicht als Summe beider an ihrer Entstehung beteiligten Kulturen, sondern vielmehr als etwas Anderes und verschiedene Logiken umfassendes Weiteres und damit als kulturelle Differenz.

Damit aber, so scheint mir, wird etwas Entscheidendes in den Blick genommen: die aktive und schöpferische Dimension dieses Prozesses, welche ja selbst im Vergessen, der „desculturación“, impliziert ist. Auch wenn die biologische Metapher, die Fernando Ortiz am Ende des Zitats betonte, wiederum eine gewisse neue Einheit nahelegt, die geeignet sein könnte, die heterogene Dimension dieser Entwicklung, dieses Prozesses und seiner Resultate, zum Verschwinden zu bringen, zeigt sich doch, dass die entstandene Kultur nicht einfach eine Summe des Vorherigen ist. Klar ist aber auch, dass die neue Kultur nicht auf eine Tabula rasa, eine kulturell leere Fläche trifft, auf die sie sich projiziert. Die abendländische Kultur begegnet nicht einer ,Nicht-Kultur ${ }^{\star}$ und führt sie auch nicht vor

19 Ortiz, Fernando: Contrapunteo cubano del tabaco y el azúcar. Prólogo y Cronología: Julio Le Riverend. Caracas: Biblioteca Ayacucho 1978, S. 96 f. 
diesem Hintergrund zur eigenen Kultur oder gar zur einzigen Kultur, indem sie sie im vollen Wortsinne akkulturiert. Vielmehr ereignet sich dieser Prozess zwischen zwei voneinander verschiedenen Kulturen. Dabei ist es entscheidend, dass in dieser Definition von Transkulturation Fernando Ortiz aus guten Gründen keinerlei Angaben über die kulturelle Wertigkeit der beteiligten Kulturformationen macht und damit jedweder abendländischen Suprematie einen Korb gibt.

Mit Hilfe einer derartigen Argumentation nimmt Ortiz der eurozentrischen und logozentrischen Vokabel der Akkulturation als Hinführung zu einer Kultur und zwar implizit zur als einzig möglich erachteten Kultur - ihre gefährliche Spitze und lässt den kulturellen Transformationsprozess als überaus komplexe und gleichgewichtige Entwicklung erscheinen, ohne einen „terminus ad quem“ festzulegen. Das Ergebnis dieses Prozesses der Transkulturation ist nicht etwa die Summe der verschiedenen Elemente, sondern etwas Neues, Eigenständiges, Originelles, das unterschiedlichen Logiken gehorcht. Entscheidend scheint mir in Fernando Ortiz' Konzeption der Transkulturation zu sein, dass die Bewegung, das Durchlaufen verschiedener Spannungsfelder, in den Mittelpunkt seiner Überlegungen rückt. Dies sollte Folgen haben.

Das Bemerkenswerte und Spannende an diesem Text ist darüber hinaus nicht nur die anthropologische oder kulturtheoretische Ebene, sondern auch die Sprache und mehr noch die Schreibweise des kubanischen Intellektuellen. Denn im Contrapunteo cubano haben wir es nicht mit der Schreibweise eines wissenschaftlichen Textes - auch wenn dies in diesem definitorischen Auszug ein wenig so wirken könnte -, sondern mit literarischen Vorbildern und insbesondere dem Dialog zwischen Don Carnal und Doña Cuaresma im Libro de Buen Amor des Arcipreste de Hita zu tun. An dessen Dialogstruktur und kontrapunktischer Bewegung lehnt sich der kubanische Text von Beginn an explizit an. Damit wird anhand eines Zwiegesprächs zwischen den Partnern Tabak und Zucker deutlich: Der Text führt uns bislang unbedachte Prozesse nicht nur auf einer Inhaltsebene, sondern auch auf der Ausdrucksebene vor Augen; und dieser letzteren wollen wir uns zunächst einmal näher zuwenden.

Die semantische und narrative Grundstruktur des Contrapunteo cubano del tabaco y el azúcar ist die kontrapunktische Gegenüberstellung von Tabak und Zucker in der kubanischen Geschichte, ein geradezu musikalisches Verfahren, welches Oppositionen erzeugt, von denen sich in der Folge weitere ableiten. Ich möchte Ihnen dies ausgehend von einer Passage vorführen, in welcher es zunächst um eine scheinbare Gleichheit von Zucker und Tabak geht, aus der aber dann grundlegende semantische und kulturelle Oppositionen abgeleitet werden:

Tabak und Zucker sind beides Produkte aus dem Pflanzenreich, die kultiviert, elaboriert, vermarktet und am Ende mit großem Genuss von menschlichen Mündern konsumiert werden. 
Bei der Produktion von Tabak und Zucker lassen sich darüber hinaus dieselben vier Elemente beobachten: Erde, Maschine, Arbeit und Geld, deren verschiedene Kombinationen ihre Geschichte darstellen. Doch von ihrem Aufkeimen im Inneren der Erde bis zu ihrem Tod im Konsum durch den Menschen verhalten sich Tabak und Zucker fast immer gegensätzlich zueinander.

Zuckerrohr und Tabak bilden völlige Kontraste. Eine Rivalität, so würde man sagen, belebt und trennt sie von der Wiege an. Die eine ist eine Graspflanze und der andere eine Nachtschattenpflanze. Die eine schießt empor, der andere kriecht aus dem Samen. [...] Die Zuckerpflanze besitzt ihren Reichtum im Schaft und nicht in ihren Blättern, die man wegwirft; des anderen Wert ist sein Blattwerk und nicht der Schaft, den man verachtet. Die Zuckerpflanze lebt lange Jahre auf dem Feld, die Tabakspflanze dort jedoch nur kurze Monate. Jene sucht das Licht, dieser den Schatten; Tag und Nacht, Sonne und Mond. Jene liebt den Regen, wie er vom Himmel fällt; dieser die Glut, wie sie von der Erde aufsteigt. Aus dem Rohr der Zuckerpflanze presst man den Zuckersaft zum Genusse; in den Blättern des Tabaks trocknet man den Saft, weil er stört. Der Zucker findet sein menschliches Schicksal im Wasser, in dem er sich auflöst und zu Sirup gerinnt; der Tabak kommt zum Menschen durch das Feuer, in welchem er sich in Rauch auflöst. Weiß ist die eine, dunkel ist der andere. Süß und geruchlos ist die Zuckerpflanze; bitter und aromatisch der Tabak. Alles voller Kontraste! Lebensmittel und Gift, Aufwachen und Einschläfern, Energie und Schlaf, Lust des Fleisches und Verzückung des Geistes, Sinnlichkeit und Ideenlehre, Appetit zur Befriedigung und Illusion, die sich in Rauch auflöst, Kalorien des Lebens und Rauchschwaden der Phantasie, ab der Wiege vulgäre und anonyme Indistinktion und aristokratische, weltweit auf Marke bedachte Individualität, Medizin und Magie, Realität und Traum, Tugend und Laster. Die Zuckerpflanze ist eine Sie; der Tabak ein Er ... Das Rohr war das Werk von Göttern, der Tabak das Produkt von Dämonen; sie ist die Tochter des Apoll, er die Ausgeburt der Proserpina ...20

Keine Angst: Dies sind bei weitem noch nicht alle Gegensatzpaare, die Fernando Ortiz in seinem Buch aufhäuft! Vergessen wir vor allem nicht das importierte Element des Zuckers und das einheimisch-amerikanische des Tabaks oder das Weiße und das Schwarze, das Weibliche und das Männliche mit ihren abgeleiteten Gegensätzen. Fernando Ortiz gestaltet dies zur grundlegenden Funktionsweise der kubanischen Wirtschaft, der kubanischen Kultur, der kubanischen Gesellschaft und des kubanischen Lebens um, wobei seine Sympathie immer wieder deutlich dem Tabak, dem männlichen, einheimischen, geistvollen Element gehört. Denn der Tabak ist individuell und nicht industriell und vermasst, er wird in Einzelarbeit und nicht in großen Zuckerrohrplantagen angebaut. Sie sehen: Dieser literarisch-wissenschaftliche Kontrapunkt eröffnet eine ganze Kulturgeschichte und erlaubt es uns, in viele zentrale Oppositionen der kubanischen Gesellschaft, Wirtschaft und Mentalität hineinzublicken. Und ganz nebenbei: Der Tabak steht

20 Ortiz, Fernando: Contrapunteo cubano del tabaco y el azúcar, S. 13 f. 
auch für das schwarze Element in der Geschichte Kubas, dem sich der Kulturanthropologe mit besonderer Sorgfalt widmete.

Die kubanische Kulturgeschichte gehorcht ganz diesem Contrapunteo, dessen Schreibweise - wie Sie bemerkt haben - äußerst geschickt die verschiedensten semantischen Ebenen einblendet, die in der Folge dann weiterentwickelt werden. Ortiz gestaltet seine in kleinen Textbausteinen, kleinen Text-Inseln entfalteten Geschichtsfragmente unter Einbeziehung aller vier Grundelemente, aller literarischen und kulturellen Symbole, die der Anthropologe aufzubieten in der Lage ist. Die semantischen, aber klanglichen Gegenüberstellungen sind auch sprachlich sehr schön durchgeführt: „El tabaco nace, el azúcar se hace.“21

Am Ende - und das muss dann in Kuba wohl so sein - zeigt sich natürlich auch, dass der Zucker sich in Alkohol, in kubanischen Rum auflöst und damit seinerseits zu Geist wird: „Y con el alcohol en las mentes“ - so der Schlusssatz des Hauptteils - „terminará el contrapunteo“.22 So versöhnen sich Tabak und Zucker doch noch in der geistvollen Umarmung einer kubanischen Zigarre, genossen mit einem Gläschen Rum. Der Humor kommt in diesem wunderschönen Text nicht zu kurz, welcher ebenso für Raucher wie für Nichtraucher, für Diabetiker wie für solche Leserinnen und Leser geeignet ist, die dem Süßen in kubanischen Mengen frönen.

Doch ist dies nicht die einzige Grundstruktur des Buches, die uns an dieser Kulturgeschichte der Insel Kuba interessiert. Denn der eigentliche Essay des Contrapunteo cubano nimmt etwa nur gut vierzig Seiten ein; die weiteren vierhundert Seiten werden durch zusätzlich angehäufte, proliferierende Kapitel in Form größerer und kleinerer Text-Inseln gebildet, welche das Textganze zu einem gewaltigen, eindrucksvollen Werk anschwellen lassen. Fernando Ortiz‘ Buch könnte in seiner Grundidee durch Alexander von Humboldt beeinflusst worden sein, der in seinen Ansichten der Natur ein Verhältnis zwischen Haupttext und Anmerkungen von bis zu 1:12 erprobt hatte, so dass sich die ,eigentlich' zentralen Texte geradezu klein ausnehmen. Wenn dieser ,eigentliche Text‘ aber nur mal mehr schlappe zehn Prozent ausmacht, worum geht es dann in Fernando Ortiz' Contrapunteo cubano wirklich?

Von Beginn an verweist der Haupttext auf ein erstes zusätzliches Kapitel, das man zunächst vielleicht sogar als Fußnote lesen oder als solche missverstehen könnte. Diese vermeintliche Fußnote erweist sich aber als eines von insgesamt fünfundzwanzig Kapiteln, die neunzig Prozent des Textes ausmachen. Schon im ersten Kapitel wird das Lesepublikum auf diese weiteren Kapitel aufmerksam

21 Ortiz, Fernando: Contrapunteo cubano, S. 16.

22 Ebda., S. 88: „Und mit dem Alkohol im Kopf geht dieser Kontrapunkt zu Ende.“ 
gemacht, da möglicherweise die Schreibweise des eigentlichen Buches zu schematisch sei. Eine fürwahr erstaunliche Leseanweisung! Im ersten Zusatzkapitel war bereits der zentrale Begriff der Transkulturation erläutert worden; doch in diesem Zusatzkapitel wird zugleich auch ein Inhaltsverzeichnis mit den weiteren Zusatzkapiteln angeboten, so dass dem Lesepublikum im Grunde zwei Lesemöglichkeiten offeriert werden. Denn entweder wird der Hauptteil plus jeweils dazugehörigem Zusatzkapitel gelesen, oder die Leserschaft liest zuerst den Hauptteil und danach die Zusatzkapitel in ihrer großen Fülle und Einteilung in schwarze und weiße, Tabak und Zucker.

Das Buch erscheint so - wie Celina Manzoni sehr schön aufzeigte ${ }^{23}$ - als mehrere Bücher ganz im Sinne von Cortázars Roman Rayuela, den wir in unserer Vorlesung über die Literaturen des 20. Jahrhunderts ausführlich besprochen haben. ${ }^{24}$ Zusätzlich dürfen bei dem Humboldt-Kenner Ortiz auch - wie bereits betont - Anleihen bei den Ansichten der Natur vermutet werden, um einer proliferierenden Textgestaltung Raum zu geben. Man kann hinter dieser Vorgehensweise nicht nur die Experimentierfreudigkeit mit verschiedenen Schreibweisen sehen - etwa der wissenschaftlichen, essayistischen, aber auch im engeren Sinne intertextuell-literarischen -, darf aber auch insgesamt vermuten, dass damit das Heterogene, nicht Homogenisierbare, das Transkulturelle gleichsam schon in der Textgestalt auf Ausdrucksebene entfaltet werden sollte. Der Contrapunteo cubano erweist sich so als hybrider, heterogener Text, den man hinsichtlich bestimmter Charakteristika durchaus bereits mit Texten der Postmoderne und deren spezifisch ästhetischen Entwürfen in Verbindung bringen darf. Die Nähe des Contrapunteo zu José Lezama Limas La expresión americana ist auf der Inhalts- wie auf der Ausdrucksebene evident und zeigt, wie einflussreich dieses literarischwissenschaftliche Werk des kubanischen Autors war.

Fernando Ortiz gelang es, in seinem zentralen (oder vielleicht doch nicht so zentralen) Essay die Geschichte Kubas zu erzählen: mit der Einführung der Zuckerrohrplantagen, der nachfolgenden Sklaverei, der Dampfmaschine, der Industrialisierung, der Kapitalisierung, dem kapitalistischen Verdrängungswettbewerb einerseits. Andererseits - auf der Seite des Tabaks - berichtet er von der Schaffung auf Qualität angelegter Strukturen außerhalb der massenhaften Sklaverei, dem bäuerlichen Kleinbesitz, der intensiven Nutzung, der Arbeiterbildung, den Vorlesern des Tabakproletariats und der damit verbundenen revolutionären Kraft der gebildeten Arbeiterschaft. In dieser Geschichte rückte die schwarze

23 Vgl. Manzoni, Celina: El ensayo ex-céntrico: el Contrapunteo de Fernando Ortiz (o algo más que un cambio de nombre). In: Filología (Buenos Aires) XXXIX, 1-2 (1996), S. 151-156.

24 Vgl. Ette, Ottmar: Von den historischen Avantgarden bis nach der Postmoderne, S. 646-660. 
Bevölkerung Kubas in den Mittelpunkt. Aber war es nur eine Geschichte der Kontraste, der Gegensätze, der Auseinandersetzung und des ständigen Kontrapunkts?

Fernando Ortiz wäre kein Kubaner gewesen, hätte er hierauf nicht eine schlüssige Antwort gehabt, die mit Humor und literarischer Bildung vorgetragen wurde und sich wiederum auf etwas Neues öffnete, in dem vielleicht aber doch mehr das Dunkle, das Satanische, das dem Tabak Verwandte fortlebt, ganz transkulturell versteht sich und längst in alle Welt exportiert. Denn es war gleichsam der heilige Rauch, der „holy smoke“, der sich bei ihm in hochgeistige Getränke auflöst. Damit erscheint die Geschichte Kubas, wie könnte es in diesem erogenen Land auch anders sein, als Liebesgeschichte mit Happy Ending nebst zahlreicher Nachfahren. Lesen wir also die letzte Seite des Hauptteils in ihrer Gesamtheit:

Es gibt daher für die Versemacher Kubas, so wie es jener zum Pícaro neigende Erzpriester, der Arcipreste de Hita, gewollt hätte, keinerlei Streitgespräch zwischen Don Tabak und Doña Zucker, sondern eher etwas Unauffälliges und Diskretes, das wie in den Märchen mit Vermählung und Glückseligkeit endet. Also mit der Hochzeit von Tabak und Zucker. Und mit der Geburt des Alkohols, empfangen in Gnade und Würde aus dem satanischen Geiste, dem Gevatter Tabak, vom süßen Leibe der unreinsten Dame Zucker. So entsteht die heilige kubanische Dreifaltigkeit: Tabak, Zucker und Alkohol. ${ }^{25}$

Die ganze Geschichte endet also glimpflich satanisch und - wie wir hinzufügen könnten - auf gut Kubanisch auch alkoholisiert paternalistisch, eben stark gezuckert. Und natürlich mit einem weiteren Exportprodukt, das ebenso auf Qualität wie auf Quantität angelegt ist, das ebenso Massenprodukt wie individualisiert ist und mit dem die Insel zu gewissen Zeiten wie zuvor mit Tabak und Zucker die Welt überschwemmte. Zur Lust und zum Vergnügen der Welt und nicht immer Kubas und der Kubaner, könnte man aus heutiger Sicht und unter Berücksichtigung der US-amerikanischen Wirtschaftsblockade der Insel hinzufügen. Aber das wäre ein anderer Contrapunteo, der in Ortiz' Text durchaus angelegt ist.

Wir dürfen an dieser Stelle noch einmal festhalten, dass es Fernando Ortiz mit seinem Konzept der Transkulturation gelang, sich von ethnozentrisch weißen Positionen zu verabschieden und zugleich einer größeren Offenheit gegenüber multiethnischen Gesellschaften entgegenzugehen, Gesellschaften, die nicht mehr einfach in einer Synthese aufgehen wie noch im Konzept des hispanoamerikanischen „mestizaje“ oder eines „Melting Pot“ nach US-amerikanischem Vorbild. Das Konzept der Transkulturalität löst sich aber auch nicht in reine Hybridität und Heterogenität auf, eine starke Zerstäubung in kulturell dauerhybridisierte Kulturfragmente, wie wir dies verstärkt seit den frühen achtziger Jahren in der

25 Ortiz, Fernando: Contrapunteo cubano, S. 88. 
Kulturtheorie Lateinamerikas vorfinden. Demgegenüber ist es zweifellos notwendig, neue Konzepte zu entwickeln, in welchen freilich der Transkulturation von Fernando Ortiz eine wichtige Rolle zukommt. ${ }^{26}$

Der kubanische Anthropologe war gleichzeitig ein Kulturtheoretiker des Übergangs und ein versierter Schriftsteller, der es verstand, als Wissenschaftler das Medium der Sprache, derer er sich bediente, nicht als transparente Glasscheibe aufzufassen, sondern selbst zum Schwingen und zum Sprechen zu bringen. Die Form des Essays, die er wählte, war dabei Medium der Verständigung über die eigene Geschichte, die eigene Herkunft und die eigene Identitätsproblematik ebenso der Kubaner wie auch der Lateinamerikaner überhaupt. Seine Theorie der Transkulturation, die auf einer ständigen und unabschließbaren Bewegung gründet und zu keinerlei Abschluss finden kann, war folgenreich in verschiedenen Disziplinen und Bereichen. Vor allem durch die Vermittlung des Uruguayers Angel Rama ${ }^{27}$ wurden Ortiz' Thesen auch wirksam im Bereich der Literaturtheorie, wo seit den siebziger Jahren von Transkulturation in der Literatur gesprochen wurde.

Dennoch sollten wir nicht vergessen, dass uns in dem Anthropologen, Historiker, Kulturtheoretiker, Musikologen, Biographen und Philosophen ein Schriftsteller von Rang entgegentritt, der sein eigenes Expertentum als Gelehrter gerade in dieser literarischen Dimension in allgemeiner Form in die Debatten um kulturelle Entfaltung und Integration der schwarzen Kulturen einbrachte. Aus dieser Stellung als Wissenschaftler und Schriftsteller, Gelehrter und Intellektueller erwächst zusätzlich zu allen bereits geäußerten Charakteristika seines Schaffens die bis heute anhaltende Aktualität des kubanischen Denkers.

Schon auf seine Zeitgenossen übte Fernando Ortiz eine ungeheure Anziehungs- und Strahlkraft aus. Neben vielen anderen zählte auch Alejo Carpentier zu den Bewunderern dieses sogenannten „dritten Entdeckers“ Kubas, dieses Entdeckers der afroamerikanischen Kulturen, die zugleich mehr sind und weniger als die afrikanischen Kulturen ihres Herkunftskontinents: Denn auch der Verlust, die „desculturación“, spielt laut Ortiz eine Rolle. Amerika ist also nicht nur Schauplatz, sondern Agens und Movens dieser Kulturen zugleich und eben dieser Ausrichtung hing auch Alejo Carpentier an.

26 Vgl. hierzu Ette, Ottmar / Wirth, Uwe (Hg.): Nach der Hybridität. Zukünfte der Kulturtheorie. Berlin: Verlag Walter Frey - edition tranvía 2014; sowie (dies., Hg.): Kulturwissenschaftliche Konzepte der Transplantation. Unter Mitarbeit von Carolin Haupt. Berlin - Boston: Walter de Gruyter 2019.

27 Vgl. Rama, Angel: Transculturación narrativa en América Latina. Montevideo: Fundación Angel Rama 1989. 
In seinem programmatischen Vorwort $\mathrm{zu}$ seinem Roman El reino de este mundo machte letzterer - unter einem Miguel de Cervantes entnommenen Motto darauf aufmerksam, dass er 1943 Haiti hatte besuchen können und die Festung sowie das Schloss La Ferrière und Sanssouci von Henri Christophe ebenso sehen konnte wie die damals noch - so Carpentier - normannische Stadt von Cap Haïtien. Zuvor hatte diese Stadt - selbstverständlich noch bei Victor Hugo - den Namen Cap Français getragen. Carpentier wäre dabei nicht Carpentier, hätte dieser Poeta doctus es nicht verstanden, auf wenigen Zeilen ungeheuer viele Verweise und Verbindungen auf und mit zahlreichen anderen literarischen Texten, aber auch nicht-literarischen Künsten herzustellen und in seine Programmatik einzubeziehen.

So durfte zwischen Van Gogh und Wifredo Lam, aber auch zwischen Cervantes und Rimbaud nichts und niemand fehlen. Neben den Verweisen auf Lautréamonts Les Chants de Maldoror, das schon die Lieblingslektüre der französischen Surrealisten gewesen war, gab es vielfältige und hintergründige Verweise auf Mythen aus den unterschiedlichsten Weltgegenden. Mackandal wird in diesem Vorwort zum lebendigen Beispiel dafür, dass der Glaube seiner Landsleute an ihn zum Ausgangspunkt einer der dramatischsten Sklavenaufstände werden konnte, die jemals auf der Insel ausbrachen und die Haitianische Revolution begründeten. Aus dieser Überfülle intertextueller Bezügen, die typisch sind für die neobarocke Schreibweise Alejo Carpentiers, entsteht am Ende dieses Epoche machenden Vorwortes eine programmatische Kampfschrift, die in der Tat jahrzehntelang die Diskussionen in Hispanoamerika, Lateinamerika und weit darüber hinaus anheizte. Schauen wir uns den Schlussabschnitt dieses Vorworts einmal genauer an:

[...] Amerika ist sehr weit davon entfernt, seinen reichen Strom an Mythologien ausgeschöpft zu haben.

Ohne es mir systematisch vorgenommen zu haben, antwortete der nachfolgende Text auf diese Serie von Besorgnissen. In ihm wird eine Abfolge von außergewöhnlichen Tatsachen erzählt, welche sich auf der Insel Santo Domingo in einer bestimmten Epoche ereigneten, die den Zeitraum eines Menschenlebens nicht überschreitet. Dabei kann das Wunderbare frei von einer Realität fließen, welche gleichwohl strikt in all ihren Details nachvollzogen wird. Denn es muss bemerkt werden, dass die Erzählung, die man gleich lesen wird, auf einer außerordentlich rigorosen Dokumentation aufruht, welche nicht allein die historische Wahrheit der Geschehnisse, der Personennamen selbst aus der zweiten Reihe, von Orten und sogar von Straßen respektiert, sondern unter seiner scheinbaren Unzeitlichkeit eine minuziöse Überprüfung von Daten und Chronologien verbirgt. Durch die dramatische Einzigartigkeit der Ereignisse, durch die phantastische Schönheit der sich begegnenden Figuren ergibt sich gleichwohl zu einem bestimmten Zeitpunkt auf der magischen Kreuzung der Stadt am Kap, dass alles wunderbar ist in einer Geschichte, die unmöglich in Europa angesiedelt werden könnte und die dennoch so real ist, wie jedes andere beispielhafte 
Geschehen, das zur pädagogischen Erbauung in den Schulhandbüchern aufgelistet wird. Aber was ist die Geschichte von ganz Amerika denn anderes als eine Chronik des Real-Wunderbaren ${ }^{28}$

Hier haben Sie also die programmatische Erklärung des „real maravilloso“, der wunderbaren Wirklichkeit, deren Chronik es zu schreiben gelte und als deren Chronist sich Alejo Carpentier verstand. Das Faszinierende an dieser Passage ist zweifellos die künstlerisch und literarisch so produktive Verbindung zwischen dem Realen und dem Wunderbaren im Sinne einer Verknüpfung, die das „maravilloso" als eine fundamentale Dimension des Realen in Amerika erscheinen lässt. Unter Amerika verstand Carpentier dabei vor allem das nicht nur iberisch, sondern auch französisch und afrikanisch oder indigen geprägte Amerika, in jedem Falle einen Subkontinent, der aus seiner Sicht zweifellos einen Kreuzungspunkt verschiedener romanischer Literaturen und Kulturen der Welt darstellte. So entsteht ein neues Verständnis dieses lateinisch mitgeprägten Latein-Amerika unter der Feder des Kubaners, wobei aus seiner karibischen Sicht den schwarzen Kulturen eine entscheidende Rolle zufiel. Die Karibik und Lateinamerika bilden auf diese Weise jenen Raum, wo sich die genannten Kulturen sowohl in interner als auch externer Relationalität in gänzlich neuer Form aufeinander eingelassen hatten und auch weiterhin einlassen konnten. Denn es war die Welt dieser Transkulturation, welche das Wunderbare in der Wirklichkeit auf Schritt und Tritt als real vor Augen führte.

Eine derartige Konzeption von Wirklichkeit brachte zunächst einmal eine ganz erhebliche Erweiterung des Realitätsbegriffs mit sich. Denn Realität stand in diesem Verständnis nicht mehr alleine unter dem Rationalitätsgebot westlicher Prägung, sondern erlaubte andere Logiken, die in dieser Wirklichkeit ebenfalls vorherrschen und wirksam werden konnten. Es ist an dieser Stelle nicht möglich, Ihnen die Konsequenzen dieser ästhetischen Eroberung in Gänze aufzuzählen, verstand es doch Carpentier, von dieser Position aus gleichsam eine Literatur sui generis basierend auf einer Realität sui generis für Lateinamerika zu reklamieren und künstlerisch umzusetzen. Dabei war diese Realität des Wunderbar-Wirklichen nicht erst im 20. Jahrhundert, sondern bereits viel früher entstanden, eine Tatsache, auf welche der Carpentier'sche Begriff der Chronik, der „crónica“, bereits aufmerksam macht.

Der ästhetische Preis für diese Wirklichkeit des Wunderbaren aber war durchaus hoch. Denn im Kontext solcher Vorstellungen wurde Lateinamerika - insbesondere im Gegensatz zu Europa - als Ort des „real-maravilloso“ essentialisiert

28 Carpentier, Alejo: El reino de este mundo (Prólogo), S. 8. 
und in eine klare Differenz zur abendländischen Rationalität gestellt. „América es diferente“ könnte hier in Anlehnung an andere Slogans das touristische Schlagwort lauten. Es war daher keineswegs zufällig, dass im abschließenden Satz auch die Chroniken auftauchten: Denn Carpentier sah den lateinamerikanischen Schriftsteller in der Rolle jener Chronisten, die den Kontinent ab dem ausgehenden 15. Jahrhundert als erste in die spanischsprachige Welt eingliederten und insbesondere dem „maravilloso“ breiten Raum in ihren Darstellungen verschafften. Standen der lateinamerikanische Schriftsteller und die lateinamerikanische Schriftstellerin folglich in der Tradition der europäischen Chronisten der Conquista einer Wirklichkeit, die sie nur zum Teil verstanden? Genau an diesem Punkte sollten später dann auch die Kritikpunkte an Alejo Carpentiers Position ansetzen.

Es wäre durchaus möglich, in diesem Zusammenhang das kurze Vorwort von Carpentier noch weiter auseinanderzunehmen, um dabei feststellen zu können, wie sehr er mit einem französischen (und surrealistisch geprägten) Literaturhorizont verbunden war und wie stark jene Bande waren, welche im transkontinentalen und inter- wie translingualen Sinne die romanischen Literaturen der Welt miteinander verbanden. Für Alejo Carpentier standen im Vordergrund dabei jene intertextuellen Beziehungen, welche aus der Kreuzung von französisch- und spanischsprachiger Welt entstehen können, zweier globalisierter romanischer Sprachen, deren Verbreitung einen nicht geringen Teil der Erdoberfläche gerade auch zwischen den Wendekreisen betrifft. Dass es bei Alejo Carpentier gerade jene Sprachen waren, mit denen er sich biographisch am stärksten identifizierte, mag ein zusätzlicher und keineswegs vernachlässigbarer Faktor gewesen sein. Doch klar ist auch, dass das Konzept des „real maravilloso“ den Zusammenhang zwischen den romanischen Literaturen der Welt einmal mehr bestärkte.

Vergessen wir dabei nicht, dass Alejo Carpentier in einer ersten Phase lange Jahre im Exil in Paris verbrachte: Es waren Jahre, die seine Einstellungen im literarischen wie im künstlerischen und politischen Sinne ganz entscheidend prägten. Lassen Sie mich an dieser Stelle - ich komme später auf diese Problematik zurück - kurz einflechten, wie wichtig das Exil nicht nur ganz allgemein für die Internationalisierung und Globalisierung von Literaturen war, sondern wie unverzichtbar Exil und Diaspora immer wieder in ganz grundlegender Weise auf die Bildung der romanischen Literaturen der Welt zurückwirkten. Man könnte ohne alle Übertreibungen behaupten, dass die lateinamerikanischen Literaturen des 19. Jahrhunderts ohne das Exil in jener Form, die wir in dieser Vorlesung kritisch aufarbeiten wollen, kaum vorstellbar gewesen wären.

Carpentiers Vertrautheit mit der französischen Kultur ist sicherlich auch eine biographische Tatsache, die uns in seine Kindheit zurückführt, als er als Kind und Jugendlicher mit den Eltern im Haus auf Französisch kommunizierte und massen- 
haft die Bücher aus der Bibliothek seines Vaters las. Aber das Exil in Paris war eine ausschlaggebende Erfahrung des erwachsenen Schriftstellers, und auf dieser Ebene wurden bei Carpentier ganz ohne Zweifel Entwicklungen von transkontinentaler Dimension im translingualen Kontext ausschlaggebend.

Noch weniger war es in der Biographie des kubanischen Schriftstellers ein Zufall, dass sich Alejo Carpentier zu einem Zeitpunkt, als sich die Dinge in der Kubanischen Revolution gerade im intellektuellen Feld nicht mehr so reibungslos und angenehm darstellten, wie sie dies zumindest perspektivisch während der enthusiastischen Anfangsjahre getan hatten, mit einem konsiderablen Diplomatenposten nach Paris zurückzog. Von Paris aus ließ er die Kubanische Revolution - wenn es not tat - hochleben, wollte die französische Hauptstadt aber auf keinen Fall mehr Mit La Habana vertauschen. Schauen wir uns als Beleg für Carpentiers Ästhetik das Ende von El reino de este mundo an, das letzte Kapitel des vierten Teiles, das Carpentier mit dem Titel „Agnus Dei“ versah und das er am Ende auf Caracas, den 16. März 1948 datierte:

Ti Noël stieg auf seinen Tisch, wobei er mit seinen gefühllosen Füßen die Einlegearbeiten malträtierte. Zur Stadt des Kaps hin war der Himmel wieder von einem Schwarz, das aus dem Rauch all der Brände entstand, wie damals in jener Nacht, in welcher er mit allen Schnecken aus dem Gebirge und von der Küste sang. Der Alte schleuderte den neuen Herren seine Kriegserklärung entgegen, wobei er seinen Untergebenen den Befehl gab, die unsäglichen Werke dieser machthungrigen Mulatten im Sturme zu nehmen. In diesem Augenblick kam vom Ozean her ein großer grüner Wind auf und fiel in die Ebene des Nordens ein, wobei er mit einem unermesslichen Brüllen über das Tal des Dondón herfiel. Und während die geköpften Stiere oben auf der Bischofsmütze noch brüllten, begannen der Lesesessel, der Paravent, die Bände der Encyclopédie, die Musiktruhe, die Puppe und der Mondfisch urplötzlich durch die Luft zu fliegen, begleitet vom Zusammenbrechen der letzten Ruinen der alten Hazienda. Alle Bäume waren mit ihren Baumkronen nach Süden gestürzt und streckten ihre Wurzeln aus der Erde. Und während der gesamten Nacht hinterließ das Meer, in eine Regenwand verwandelt, Salzspuren an den Flanken der Berge.

Und von jener Stunde an wusste niemand mehr etwas von Ti Noël noch von seiner grünen Weste mit ihren lachsfarbenen Stickereien, vielleicht jener nass gewordene Geier, der von all diesem Tode bedacht mit ausgebreiteten Flügeln auf die Sonne wartete: ein Kreuz an Federn, das sich schließlich spannte und in den Tiefen von Bois Caimán verschwand. ${ }^{29}$

Am Ende des Romans steht der magische Ort von Bois Caimán, jener Ort also, der zum Ausgangspunkt der Haitianischen Revolution wurde und von dem aus ein entlaufener schwarzer Sklave namens Bouckman ein unmenschliches Kolonialregime zum Wanken und schließlich zum Einsturz brachte. Dass die Dialektik der Revolution nicht unmittelbar zum Paradies führt, hatten wir bei Carpentier

29 Carpentier, Alejo: El reino de este mundo, S. $135 \mathrm{f}$. 
bereits in El siglo de las luces gesehen. Carpentier wusste von der Dialektik der Aufklärung, auch wenn er sich davor hütete, Anmerkungen zur Revolution anzubringen, die in Kuba hätten kritisch gedeutet werden können.

In dieser barocken Szenerie von Zerstörung und Verwüstung am Ende von El reino de este mundo wird deutlich, dass jene Welt, welche die Haitianische Revolution aus den Angeln gehoben hatte, nur noch in den Bruchstücken - zu denen auch die französische Encyclopédie und damit ein Kernbestand der Aufklärung gehört - eines alten Systems auftaucht. Längst war die alte Herrschaft der Weißen durch andere Herrschaftsverhältnisse unter Führung der Mulatten ersetzt worden. Schon König Henri Christophe hatte demonstriert, wie die Herrschaft wieder mit Hilfe staatsterroristischer Mittel und Gewalt ausgeübt werden konnte, wie ein neu etabliertes System der Macht sich derselben Methoden bedienen konnte, damit eine kleine Elite freier Mulatten über die Massen der Sklaven gebieten würde, um sich hemmungslos zu bereichern und eigene Interessen $\mathrm{zu}$ verfolgen. Die Geschichte nach der Haitianischen Revolution schickte sich an, sich als Farce zu wiederholen.

Aber Ti Noël ist noch nicht tot. Gewiss, er ist dieses Lebens müde und verflucht eine Welt, die im Lichte des Magisch-Wunderbaren seine Wut und Empörung aufnimmt und ihre eigenen Zeichen zurücksendet. Alle Elemente des Kosmos stehen miteinander im Bunde und entbinden Kräfte, die Ti Noël noch immer zu bündeln vermag: Es sind Kräfte der Zerstörung. So bleiben nur noch Ruinen zurück und der magische Flügelschlag einer Natur, deren grüne Winde im Einklang mit magischen Energien stehen. Kein Zweifel: Die schwarzen Flügel des Geiers über Bois Caimán sind Teil der Realität und zugleich Teil des Wunderbaren! Verstehen aber, so die These Carpentiers, könne man die Geschichte Haitis - und letztlich ganz Lateinamerikas - nur, wenn man beide, das Reale wie das Wunderbare, in ihren komplementären Logiken zusammennimmt und lernt viellogisch zu denken.

Wie sonst wäre eine Revolution zu begreifen, in der die Glaubensvorstellungen der Sklaven und die magische Ausstrahlungskraft ihrer Anführer gleichwertig sind mit historischen Ereignissen wie den von Militär geschützten Rückzugsbewegungen der Weißen oder der von Napoleon befohlenen Entsendung eines großen französischen Rückeroberungsheeres unter General Leclerc? Ging dieses nicht unter der Macht und Magie der Tropenkrankheiten - insbesondere des Gelbfiebers - jämmerlich zu Grunde? Es konnte wohl kaum ein besseres Thema für den mit französischer Geschichte und Literatur bestens vertrauten Carpentier geben, um seine Vorstellungen von der intimen Verwicklung von Realem und Wunderbarem an einem konkreten historischen Gegenstand vorzuführen.

Nicht von ungefähr steht so am Ende eines Romans, der den Anspruch erheben darf, in gewisser Weise ein historischer Roman zu sein, die wundersam-wunderbare Verwandlung eines Menschen namens Ti Noël in einen Vogel. Er mutiert 
in jenen Geier, dessen Silhouette sich dunkelschwarz über den Umrissen eines Haiti zeigt, über dem noch immer die dunklen Rauchschwaden der Revolution, des Gelobten Landes, der „Tierra Prometida“, aufsteigen. Nein, die Geschichte ist noch nicht zu Ende - weder die Geschichte Haitis noch die Geschichte eines weltweiten Rassismus!

Nach diesem Exkurs, der uns nicht zuletzt mit den Dimensionen des Transkulturellen vertraut machte, kehren wir wieder zurück ins 19. Jahrhundert und fragen uns, wie denn die Geschichte des Romans in Lateinamerika begann, jener Gattung also, deren Aufstieg wir im 19. Jahrhundert präzise verfolgen werden und die im 20. Jahrhundert den lateinamerikanischen Roman zu weltweiten Erfolgen führen sollte. Dabei fragen wir uns in einem noch umfassenderen Sinne: Wie war es um jene transatlantischen Beziehungen zu einem Zeitpunkt bestellt, als sie während der Kolonialzeit noch ganz im Zeichen einer radikalen Asymmetrie zwischen beiden Welten standen? Diesen Themen wollen wir in einem kurzen Einführungskapitel nachspüren, um unsere Beschäftigung mit den sich im 19. Jahrhundert herausbildenden lateinamerikanischen Literaturen zu begründen. 